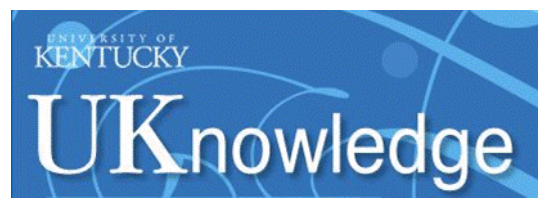

University of Kentucky

UKnowledge

$10-22-2020$

\title{
Oxidation of Phenolic Aldehydes by Ozone and Hydroxyl Radicals at the Air-Water Interface
}

\author{
Md Sohel Rana \\ University of Kentucky, mdsohelrana@uky.edu \\ Marcelo I. Guzman \\ University of Kentucky, marcelo.guzman@uky.edu
}

Follow this and additional works at: https://uknowledge.uky.edu/chemistry_facpub

Part of the Physical Chemistry Commons

Right click to open a feedback form in a new tab to let us know how this document benefits you.

\section{Repository Citation}

Rana, Md Sohel and Guzman, Marcelo I., "Oxidation of Phenolic Aldehydes by Ozone and Hydroxyl Radicals at the Air-Water Interface" (2020). Chemistry Faculty Publications. 185.

https://uknowledge.uky.edu/chemistry_facpub/185

This Article is brought to you for free and open access by the Chemistry at UKnowledge. It has been accepted for inclusion in Chemistry Faculty Publications by an authorized administrator of UKnowledge. For more information, please contact UKnowledge@lsv.uky.edu. 
Oxidation of Phenolic Aldehydes by Ozone and Hydroxyl Radicals at the Air-Water Interface

\section{Digital Object Identifier (DOI)}

https://doi.org/10.1021/acs.jpca.0c05944

Notes/Citation Information

Published in The Journal of Physical Chemistry. A, v. 124, issue 42.

Copyright $\odot 2020$ American Chemical Society ACS AuthorChoice with CC-BY-NC-ND license 


\title{
Oxidation of Phenolic Aldehydes by Ozone and Hydroxyl Radicals at the Air-Water Interface
}

\author{
Md. Sohel Rana and Marcelo I. Guzman*
}

Cite This: J. Phys. Chem. A 2020, 124, 8822-8833

Read Online

ABSTRACT: Biomass burning releases highly reactive methoxyphenols into the atmosphere, which can undergo heterogeneous oxidation and act as precursors for secondary organic aerosol (SOA) formation. Understanding the reactivity of such methoxyphenols at the air-water interface is a matter of major atmospheric interest. Online electrospray ionization mass spectrometry (OESI-MS) is used here to study the oxidation of two methoxyphenols among three phenolic aldehydes, 4-hydroxybenzaldehyde, vanillin, and syringaldehyde, on the surface of water. The OESI-MS results together with cyclic voltammetry measurements at variable $\mathrm{pH}$ are integrated into a mechanism describing the heterogeneous oxidative processing of methox-

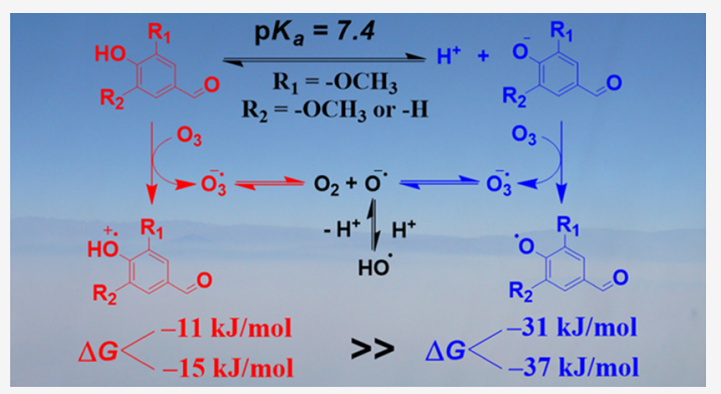
yphenols by gaseous ozone $\left(\mathrm{O}_{3}\right)$ and hydroxyl radicals $\left(\mathrm{HO}^{\circ}\right)$. For a low molar ratio of $\mathrm{O}_{3} \leq 66 \mathrm{ppbv}$, the OESI-MS spectra show that the oxidation is dominated by in situ produced $\mathrm{HO}^{\bullet}$ and results in the production of polyhydroxymethoxyphenols. When the level of $\mathrm{O}_{3}$ increases (i.e., $\geq 78$ times), the ion count of polyhydroxymethoxyphenols increases, while new ring fragmentation products are generated, including conjugated aldehydes and double bonds as well as additional carboxylic acid groups. The interfacial reactivity of methoxyphenols with $\mathrm{O}_{3}$ and $\mathrm{HO}^{\bullet}$ is enhanced as the number of methoxy $\left(-\mathrm{OCH}_{3}\right)$ groups increases (4-hydroxybenzaldehyde < vanillin < syringaldehyde). The experimental observations are summarized in two reaction pathways, leading to the formation of (1) hydroxylated methoxyphenols and (2) multifunctional carboxylic acids from fragmentation of the aromatic ring. The new highly oxygenated products with low volatility are excellent precursors for aqueous SOA formation.

\section{INTRODUCTION}

Biomass burning of lignocellulosic plants and woods from natural wildfires and anthropogenic activities can contribute up to $90 \%$ of all primary organic carbon emitted globally from combustion sources. ${ }^{1}$ Furthermore, biomass burning contributes $62 \%$ of the ca. $8.0 \mathrm{Tg} \mathrm{y}^{-1}$ black carbon and $93 \%$ of the ca. 33.9 $\mathrm{Tg} \mathrm{y}^{-1}$ organic carbon emitted from combustion globally. ${ }^{2}$ The polymeric composition of the cell wall of plants is dominated by lignin, which during biomass burning releases phenols and methoxyphenols (MPs) into the air. For example, the composition of aerosol obtained from a study on burning woods contained 21 and $45 \%$ by mass of phenols and MPs, respectively. ${ }^{3}$ Thus, MPs constitute the most abundant aromatic species emitted into the atmosphere during biomass burning $^{3-5}$ at rates that have been quantified in the gas phase to vary between 1200 and $1500 \mathrm{mg}$ per $\mathrm{kg}$ of fuel, depending on the type of wood. ${ }^{6}$ MP markers for wood combustion have also been identified in aerosol, fog, and cloud water. ${ }^{7-10}$ In addition, the atmospheric photo-oxidation of MPs can generate light-absorbing molecules in the UV-visible spectrum, which contributes to the brown carbon species found in secondary organic aerosol (SOA). ${ }^{11,12}$ The interaction of SOA with light has been proposed as a key player altering the Earth's radiation budget. ${ }^{11-19}$
Recently, the interfacial oxidation of phenols and MPs derived from benzene, toluene, and anisole has been reported as important for the formation of SOA precursors. ${ }^{20,21}$ However, the interfacial reactivity of phenolic aldehydes such as 4-hydroxybenzaldehyde (4-HBA), vanillin (VL), and syringaldehyde (SA), three important markers of biomass burning, needs to be elucidated. The large Henry's law constants at $298 \mathrm{~K}$ for 4-HBA $\left(1.96 \times 10^{6} \mathrm{M} \mathrm{atm}^{-1}\right)$, VL $(4.65$ $\left.\times 10^{5} \mathrm{M} \mathrm{atm}^{-1}\right)$, and SA $\left(4.39 \times 10^{5} \mathrm{M} \mathrm{atm}^{-1}\right)$ suggest $^{22}$ that these surfactant species can accommodate at the air-water interface and even partition into the aqueous phase. Under such atmospheric conditions, these species can be transformed by oxidants such as gaseous ozone $\left(\mathrm{O}_{3}\right)$ and hydroxyl radicals $\left(\mathrm{HO}^{\bullet}\right)$ on the surface of water. ${ }^{20,21}$ The homogeneous photooxidative processing of SA dissolved in water has been reported to produce oligomeric and ring-opening products. ${ }^{23}$

Received: June 29, 2020

Revised: August 31, 2020

Published: September 15, 2020

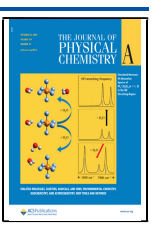


In this work, the oxidative processing of the three phenolic aldehyde markers, 4-HBA, VL, and SA, is explored at the airwater interface to provide new mechanistic insights that explain the composition of aged biomass burning-derived SOA. The use of surface-sensitive online electrospray ionization mass spectrometry (OESI-MS) allows exploring directly the functionalization and fragmentation of the selected phenolic aldehydes by $\mathrm{O}_{3}$ and $\mathrm{HO}^{\bullet}$ at the air-water interface. ${ }^{20,21,24,25}$ The heterogeneous processes are studied at environmentally relevant low $\mathrm{O}_{3}$ levels (e.g., molar ratio $\leq 66$ ppbv) during reactions lasting a microsecond with ion detection within a millisecond. Mass spectrometric data are used to identify reaction products and propose reaction pathways that can form the polyfunctional carboxylic acids prevalent in atmospheric aerosols in dissimilar geographical locations. ${ }^{26-28}$

\section{EXPERIMENTAL SECTION}

All experiments were similarly conducted as described in the methods of the previous related works. ${ }^{20,21,24}$ In brief, fresh 1.0 $\mathrm{mM}$ stock solutions of the phenolic aldehydes, VL (Alfa Aesar, 99.9\%) and 4-HBA (Sigma-Aldrich, 98.7\%), were directly prepared in ultrapure water $(18.2 \mathrm{M} \Omega \mathrm{cm}$, ELGA PURELAB flex, Veolia), while fresh 50.0 mM SA (Alfa Aesar, 99.2\%) was first prepared in acetonitrile (EMD Millipore, LC/MS grade). All stocks were then diluted in ultrapure water to provide a final phenolic aldehyde concentration of $50 \mu \mathrm{M}$. These $50 \mu \mathrm{M}$ working concentrations for OESI-MS experiments are comparable to those used in the related photochemical studies in water. ${ }^{29,30}$ The molar fraction of acetonitrile after final dilution of the SA stock, $x_{\mathrm{CH}_{3} \mathrm{CN}}=3.5 \times 10^{-4}$, is negligible. Thus, the trace of acetonitrile present in the aqueous SA solution does not affect the reactivity and product distribution observed. All experiments were conducted with solutions freshly adjusted by addition of drops of $0.001,0.010$, or 0.100 $\mathrm{M} \mathrm{NaOH}$ (AMRESCO, $\geq 97 \%$ ) to $\mathrm{pH} \geq 6.00$ or $0.001 \mathrm{M} \mathrm{HCl}$ (EMD, 37.7\%) to $\mathrm{pH} \leq 5.07$, as verified with a calibrated $\mathrm{pH}$ meter (Thermo Scientific). The $\mathrm{pH}$ range studied covers natural tropospheric conditions of different environments. ${ }^{31-33}$ The phenolic aldehydes are verified to be stable during the timescale of the experiment under the $\mathrm{pH}$ working conditions (Figures S1-S3, Supporting Information).

The concentration of phenolic aldehydes selected is justified by the reported molar ratio of this class of compounds from biomass burning that can range from 2 to 50 ppbv. ${ }^{34-36}$ From the predicted partitioning in water by Henry's law, the selected concentrations represent realistic low phenolic aldehyde levels that can be encountered in tropospheric particles and atmospheric water in the vicinity of biomass burning pollution sites. ${ }^{9}$ Similarly, tropospheric ozone molar ratios typically vary from 10 to $80 \mathrm{ppbv}$, depending on the geographical location, its proximity to pollution sources, and the season and time of the day. ${ }^{18,37-40}$ Thus, the oxidation of phenolic aldehydes at low ozone levels (e.g., $\leq 66$ ppbv) was explored, but higher molar ratios (e.g., ca. $5100 \mathrm{ppbv}$ ) were also useful to reveal important oxidative processing steps.

The selected phenolic aldehyde solution at fixed $\mathrm{pH}$ was infused at a rate of $50 \mu \mathrm{L} \mathrm{min}{ }^{-1}$ into a calibrated OESI-MS setup (Scheme 1) that has been customized from a Thermo Scientific MSQ Plus instrument. ${ }^{20,21,24,25}$ The operating conditions for OESI-MS measurements were set to a nebulizer voltage of $-1.9 \mathrm{kV}$, a cone voltage of $40 \mathrm{~V}$, a nebulizer pressure of 70 psi $\mathrm{N}_{2}(\mathrm{~g})$, and a drying gas temperature of $250{ }^{\circ} \mathrm{C}$. In
Scheme 1. Online Electrospray Ionization Mass Spectrometry (OESI-MS) Reactor Diagram

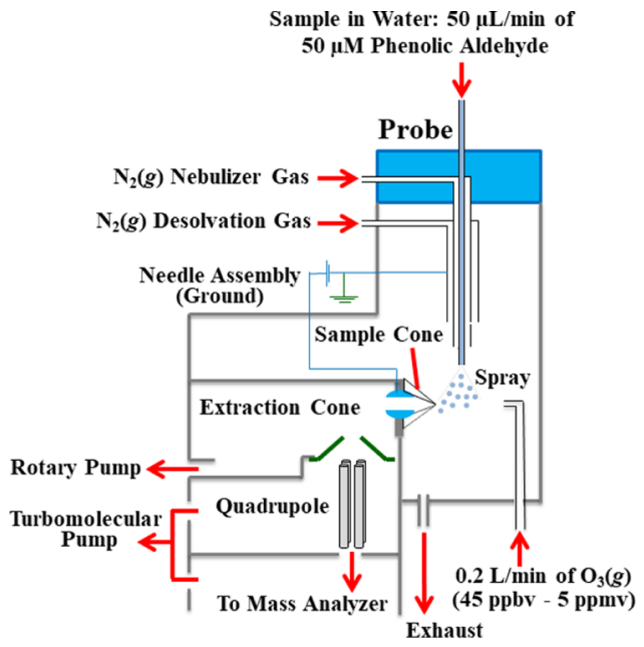

this instrument (Scheme 1), the pneumatically aerosolized solutions forming micrometer-sized droplets at atmospheric pressures were encountered by a $0.2 \mathrm{~L} \mathrm{~min}^{-1}$ flow of $\mathrm{O}_{3}(\mathrm{~g})$ reacting with a contact time of a microsecond to generate the oxidized species detected in a microsecond as anions at specific mass to charge ratios $(\mathrm{m} / \mathrm{z})$.

Ozone was generated using a spark discharge ozone generator (Ozone Solutions) fed with $\mathrm{O}_{2}(\mathrm{~g})$ (Scott-Gross, UHP) and diluted using $\mathrm{N}_{2}(\mathrm{~g})$ (Scott-Gross, UHP), and the resulting concentration was monitored by a spectrophotometer (Thermo Scientific Evolution Array UV-Visible). The molar ratio of $\mathrm{O}_{3}$ reported in the figures corresponds to the 61 times final dilution value obtained from diluting with the $\mathrm{N}_{2}(\mathrm{~g})$ nebulizing gas $\left(12.0 \mathrm{~L} \mathrm{~min}{ }^{-1}\right){ }^{24}$ The reported mass spectrometry data were acquired in the negative mode at fixed time intervals (i.e., time $\geq 1 \mathrm{~min}$ ) after background subtraction of the solvent. Following the previous protocols, all identified species are indicated by their $m / z$ values, as shown in the text, figures, and schemes. ${ }^{20,21,24}$

The OESI-MS experiments specifically involve interfacial oxidation reactions as depicted by four steps: (1) the oxidation reaction takes place in the early stage of aerosolization, right upon the uptake of $\mathrm{O}_{3}(\mathrm{~g})$ molecules on the interface of aqueous microdroplets containing the aldehydic phenol. (2) The reacted first-generation droplets undergo evaporation accompanied by fission in smaller droplets that experience charge crowding on the surface, with repulsion overcoming the surface tension. (3) The production of the anions detected takes place from the latest progeny droplets that are the direct precursor to form the ions that reach the detector. Thus, the ions are sputtered off the surface as the charge builds up, making the experiment surface sensitive. ${ }^{20,21,24,25,41,42}$ Solvent and gas-phase molecules are pumped away in the intermediate vacuum stage between the OESI probe and analyzer. (4) The ionized species are attracted toward the lower pressure orifice of the entrance cone, from where the ions travel through the entrance capillary at a lower pressure to a quadrupole mass analyzer (accurate to $0.17 \mathrm{amu}$ ) for detection at specific $\mathrm{m} / \mathrm{z}^{-}$ ratios. The OESI-MS flow-through reactor for probing fast oxidations at the air-water interface has been comprehensively described. $^{24,42}$ In addition, OESI-MS demonstrated that the interfacial $\mathrm{p} K_{\mathrm{a}}$ of acetic and pyruvic acids reduced by 2.8 and $1.8 \mathrm{pH}$ units, respectively, during the partitioning of gas-phase 
molecules on the surface of water. ${ }^{41}$ This setup has advanced the understanding of how oxidations occur on the surface of water. $^{20,21,24,25}$ Moreover, OESI-MS has been validated to be surface-sensitive by detecting the same products during in situ studies under a microsecond contact time and after offline analysis of surface reactions lasting a few hours. ${ }^{20,43}$ In conclusion, although oxidations in the liquid bulk of these water-soluble compounds should proceed by similar (or the same) reactions reported below, they are not sampled using this OESI-MS method.

The redox potential of phenolic aldehydes was determined at $\mathrm{pH} 4.98,6.01,7.04,8.03,9.04$, and 10.04 using cyclic voltammetry with an electrochemical workstation (CHI-660A, $\mathrm{CH}$ Instruments, Austin, TX) in a three-electrode configuration cell. The working electrode was a glassy carbon electrode (GCE) with a diameter of $3.0 \mathrm{~mm}$. The GCE was polished with alumina powder $(0.05 \mu \mathrm{m})$ on a microcloth polishing pad, then washed thoroughly with deionized water, and finally sonicated for $10 \mathrm{~s}$ to remove any excess alumina powder. The other two electrodes were $\mathrm{Ag} / \mathrm{AgCl}$ as a reference electrode and platinum as a counter electrode. Analyte solutions of $1.0 \mathrm{mM}$ concentration were prepared in $1.0 \mathrm{M}$ $\mathrm{KCl}$ (MP Biomedicals LLC, $\geq 99 \%$ ) from the stock solutions mentioned above. The solutions were $\mathrm{pH}$-adjusted with 0.010 $\mathrm{M} \mathrm{HCl}$ or $0.010 \mathrm{M}, 0.100 \mathrm{M}$, and $1.000 \mathrm{M} \mathrm{NaOH}$ solutions, measured with the $\mathrm{pH}$ meter, and transferred to a $50.0 \mathrm{~mL}$ class A volumetric flask for final dilution in the supporting electrolyte solution. The potential was determined from -50 to $1200 \mathrm{mV}$ against the reference electrode at a $50 \mathrm{mV} \mathrm{s}^{-1}$ scan rate. The voltammogram of the supporting electrolyte (e.g., at $\mathrm{pH} 8.00$ as a background solvent) was verified to not overlap with the analytes. Duplicate measurements for each analyte were performed at room temperature to calculate their mean and standard deviation. The detailed processing of cyclic voltammetry data is provided in the Supporting Information.

\section{RESULTS AND DISCUSSION}

OESI-MS Analysis. Figure 1 shows the OESI-MS spectra of the aerosolized aqueous solution of $4-\mathrm{HBA}\left(\mathrm{p} K_{\mathrm{a}, 4-\mathrm{HBA}}=7.61\right.$ at

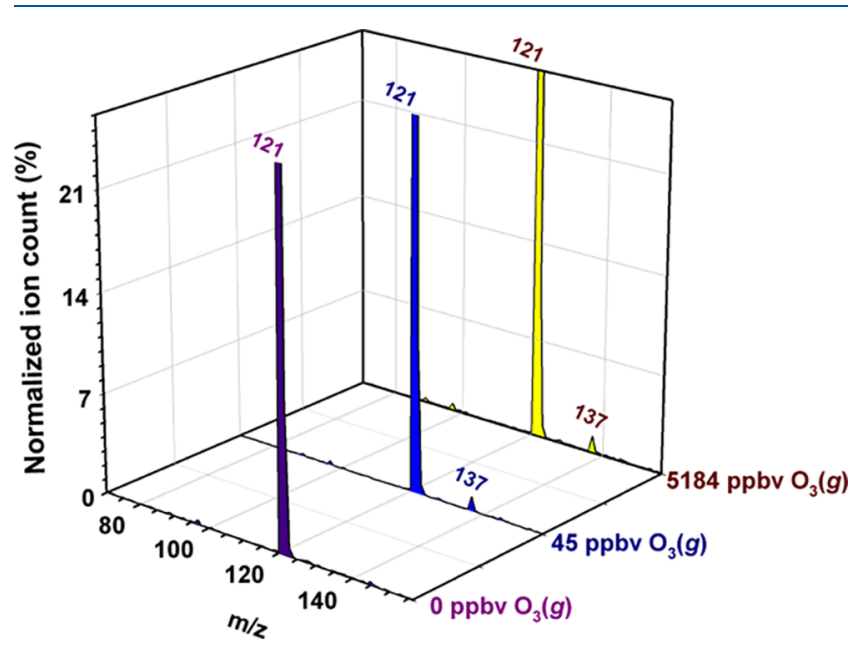

Figure 1. OESI-MS spectra of $50 \mu \mathrm{M}$ aqueous solution of 4-HBA at $\mathrm{pH} 8.0$ exposed to a $0.2 \mathrm{~L} \mathrm{~min}^{-1}$ flow of gas with or without $\mathrm{O}_{3}(\mathrm{~g})$, as indicated in the labels. Ion count values $(I)$ are normalized percentages relative to the most intense peak in each mass spectrum at $m / z 121, I_{121}$.
$298 \mathrm{~K})^{44}$ in the absence and presence of 45 and $5184 \mathrm{ppbv}$ $\mathrm{O}_{3}(\mathrm{~g})$. When no $\mathrm{O}_{3}(\mathrm{~g})$ is present in the impinging gas encountering the microdroplets $\left[0 \mathrm{ppbv} \mathrm{O}_{3}(\mathrm{~g})\right]$, the only species observed in the mass spectrum at $\mathrm{m} / z 121$ (Figure 1) corresponds to the anion of 4-HBA generated from the loss of a phenolic proton. Therefore, 4-HBA is stable, unless $\mathrm{O}_{3}(\mathrm{~g})$ is added to the reactor. For example, Figure 1 also shows the oxidation of the carbonyl group of 4-HBA on the surface of water at a low $\mathrm{O}_{3}(\mathrm{~g})$ level $(45 \mathrm{ppbv})$, with the peak of a product at $\mathrm{m} / z \quad 137$ assigned to 4-hydroxybenzoic acid observed in the mass spectrum. ${ }^{45}$ The normalized ion count of this product, $I_{137}$, slightly increases with exposure to 5184 $\operatorname{ppbv~}_{3}(\mathrm{~g})$, as shown in Figure 1, indicating that the efficiency for its formation is limited by the low reactivity of 4-HBA rather than by the availability of $\mathrm{O}_{3}(\mathrm{~g})$. Alternatively, an isomer with $m / z 137$ could have been assigned to the monoanion of 3,4-dihydroxybenzaldehyde (a hydroxylation product). ${ }^{20,21}$ However, the absence of heavier products strongly suggests the dominant oxidation to 4-hydroxybenzoic acid, with a stronger deactivating electron-withdrawing group of the aromatic ring than 4-HBA, which inhibits any further reactivity in the microseconds timescale.

Figure 2 shows the reactivity of $\mathrm{VL}\left(\mathrm{p} K_{\mathrm{a}, \mathrm{VL}}=7.38\right.$ at 298 $\mathrm{K})^{46}$ on the surface of water when exposed or not to $\mathrm{O}_{3}(\mathrm{~g})$. In

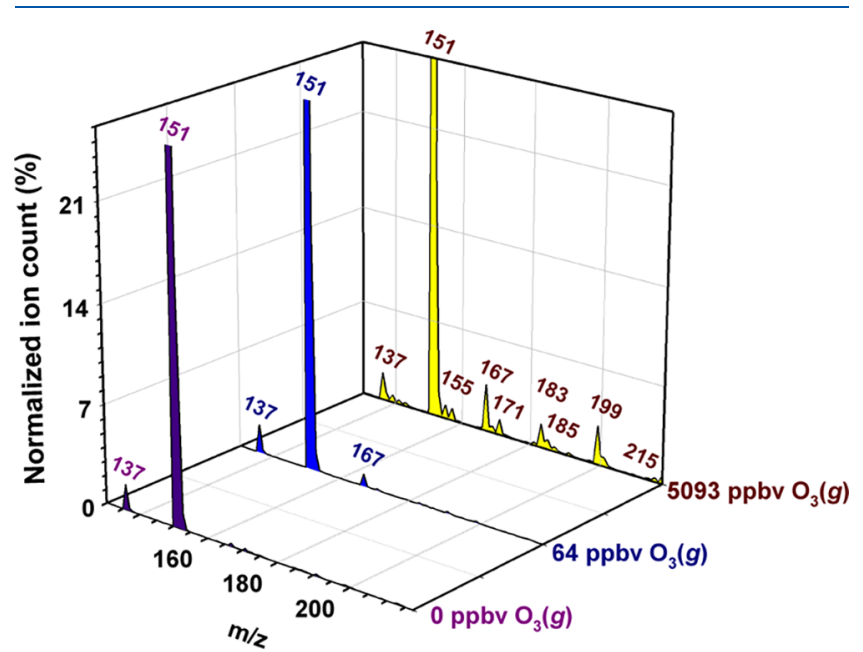

Figure 2. OESI-MS spectra of $50 \mu \mathrm{M}$ aqueous solution of $\mathrm{VL}$ at $\mathrm{pH}$ 8.0 exposed to a $0.2 \mathrm{~L} \mathrm{~min}^{-1}$ flow of gas with or without $\mathrm{O}_{3}(\mathrm{~g})$, as indicated in the labels. Ion count values are normalized percentages relative to the most intense peak in each mass spectrum, $I_{151}$.

the absence of ozone, the reagent peak of VL is stable, as observed for the abundant anion at $\mathrm{m} / z 151$ with a minor fragment ion at $m / z 137$ from the loss of 14 amu characteristic of MP breakup by collision-induced dissociation (CID). During exposure to $64 \mathrm{ppbv} \mathrm{O}_{3}(\mathrm{~g})$, a new product peak is observed at $m / z 167$, which can be assigned to either isomer 5hydroxyvanillin or vanillic acid. When VL is exposed to 5093 ppbv $\mathrm{O}_{3}(\mathrm{~g})$, the peak at $\mathrm{m} / z 167$ increases considerably, and several new products can be noticed in the mass spectrum. For example, the peaks at $\mathrm{m} / z \quad 183$ are assigned to 2,5dihydroxyvanillin or 4-formylmuconic acid monomethyl ester. The peak at $\mathrm{m} / z 199$ is due to 2,5,6-trihydroxyvanillin, 4-carboxymuconic acid monomethyl ester, or 4-formyl-5hydroxymuconic acid monomethyl ester, while the peak at $\mathrm{m} / z 215$ is assigned to 2,5,6-trihydroxyvanillic acid or to 2carboxy-5-hydroxymuconic acid monomethyl ester. The CID 
decarboxylation of the species with $m / z 215$ yields the peak observed at $m / z 171$. Furthermore, the small peak at $m / z 185$ can be explained by the generation of 4-formyl-2-hydroxymuconic acid or an isomer. Decarboxylation of 4-carboxymuconic acid methyl ester with $m / z 199$ can generate the peak observed at $m / z 155$ assigned to muconic acid methyl ester.

Figure 3 displays the result of the oxidation of $\mathrm{SA}\left(\mathrm{p} K_{\mathrm{a}, \mathrm{SA}}=\right.$ 7.34 at $298 \mathrm{~K})^{47}$ on the surface of water exposed to a flow of

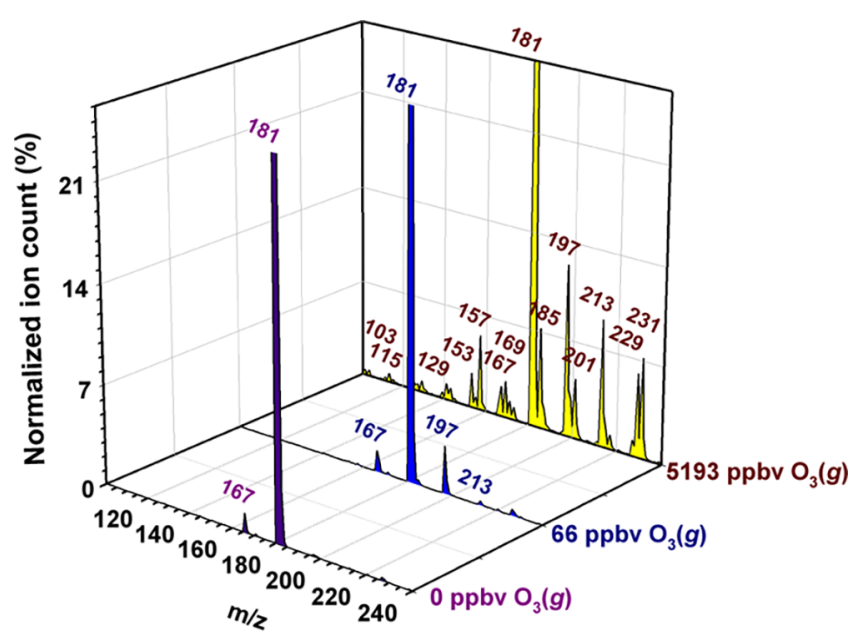

Figure 3. OESI-MS spectra of $50 \mu \mathrm{M}$ aqueous solution of syringaldehyde at $\mathrm{pH} 8.0$ exposed to a $0.2 \mathrm{~L} \mathrm{~min}^{-1}$ flow of gas with or without $\mathrm{O}_{3}(\mathrm{~g})$, as indicated in the labels. Ion count values are normalized percentages relative to the most intense peak in each mass spectrum, $I_{181}$.

$0.2 \mathrm{~L} \mathrm{~min}^{-1}$ with 0,66 , and $5152 \mathrm{ppbv}_{3}(\mathrm{~g})$. In the absence of $\mathrm{O}_{3}(\mathrm{~g})$, only the anion of SA at $\mathrm{m} / z 181$ is registered in the mass spectrum together with a small CID fragment loss of 14 amu characteristic of MPs at $m / z 167$. New products appeared in the mass spectrum upon the addition of 66 and $5152 \mathrm{ppbv}$ $\mathrm{O}_{3}(\mathrm{~g})$. In more detail, the oxidation product peak with $\mathrm{m} / \mathrm{z}$ 197 can be assigned to 2-hydroxysyringaldehyde or less likely to syringic acid. The peak at $m / z 213$ could correspond to the formation of 4-formyl-2-methoxymuconic acid methyl ester and 2,6-dihydroxysyringaldehyde or 2-hydroxysyringic acid. The product peak at $m / z 229$ can be assigned to 2,6dihydroxysyringic acid and 4-formyl-2-methoxy-5-hydroxymuconic acid methyl ester. Alternative products could be generated depending on the position for hydroxyl radical $\left(\mathrm{HO}^{\bullet}\right)$ attack or the specific aromatic bond that is broken during oxidation by $\mathrm{O}_{3}$. However, the initial oxidation by $\mathrm{HO}^{\bullet}$ of the aldehyde side chain is less favorable in the aqueous phase than the direct attack to ring positions activated by electron-donating groups. ${ }^{48}$

Importantly, the peak at $\mathrm{m} / z 167$ (Figure 3) can also be assigned to 5-hydroxyvanillin in the presence of ozone, when $\mathrm{HO}^{\bullet}$ radicals substitute $-\mathrm{OCH}_{3}$ that is eliminated as methanol through oxidative demethoxylation. ${ }^{48}$ The normalized ion count of this peak in the absence of ozone is $0.2 \%$ and increases to 0.9 and $2.2 \%$ for 66 and $5152 \mathrm{ppbv} \mathrm{O}_{3}(\mathrm{~g})$, respectively. In the case of replacing both methoxides, gallaldehyde is formed at $m / z 153$, which by additional substitution of $-\mathrm{H}$ by $-\mathrm{OH}$ generates 1,2,3,4-tetrahydroxybenzaldehyde at $m / z 169$. Alternatively, hydroxylation of gallaldehyde $(m / z 153)$ produces gallic acid $(m / z 169)$, which after ring cleavage by $\mathrm{O}_{3}$ is converted into 3-carboxy-5hydroxymuconic acid $(\mathrm{m} / z 201)$. The last compound is a $\beta$ dicarboxylic acid that easily decarboxylates ${ }^{49}$ into 2 -hydroxymuconic acid $(m / z 157)$. Polihydroxylation of the aromatic ring of SA forms pentahydroxybenzoic acid also at $m / z 201$, a minor contribution to its total ion count. Gallaldehyde also serves as an important precursor to generate 3-formyl-5hydroxymuconic acid $(m / z 185)$, when direct ozonolysis breaks the aromatic ring.

The decarboxylative fragmentation by CID of syringic acid was experimentally confirmed to contribute a product at $\mathrm{m} / z$ 153 with an ion count of only $1.6 \%$ relative to that of the parent peak. Therefore, it would be expected that the peak at $m / z 229$ (e.g., 2,6-dihydroxysyringic acid) must not be the source for $m / z$ 185. Other peaks observed in the mass spectrum shown in Figure 3 originate from the ring fragmentation pathway of freshly formed hydroxyl-substituted phenolic aldehydes. ${ }^{20,21}$ The list of such products includes 4formyl-2-,3,5-trihydroxymuconic acid monomethyl ester $(\mathrm{m} / z$ 231), maleic acid methyl ester $(m / z 129)$, maleic acid $(m / z$ $115)$, and oxalic acid methyl ester $(\mathrm{m} / z 103)$.

For the fixed $\tau_{\mathrm{c}}=1 \mu \mathrm{s}$ in the setup, the experiments below explored a progressive increment of $\left[\mathrm{O}_{3}(\mathrm{~g})\right]$ from 45 to 66 ppbv up to 5 ppmv (Figure 4), to provide useful information on the interfacial reactions as if they occur during longer exposure timescales. Figure 4 shows how the ion count for the major oxidation products and the three reactants, as shown in

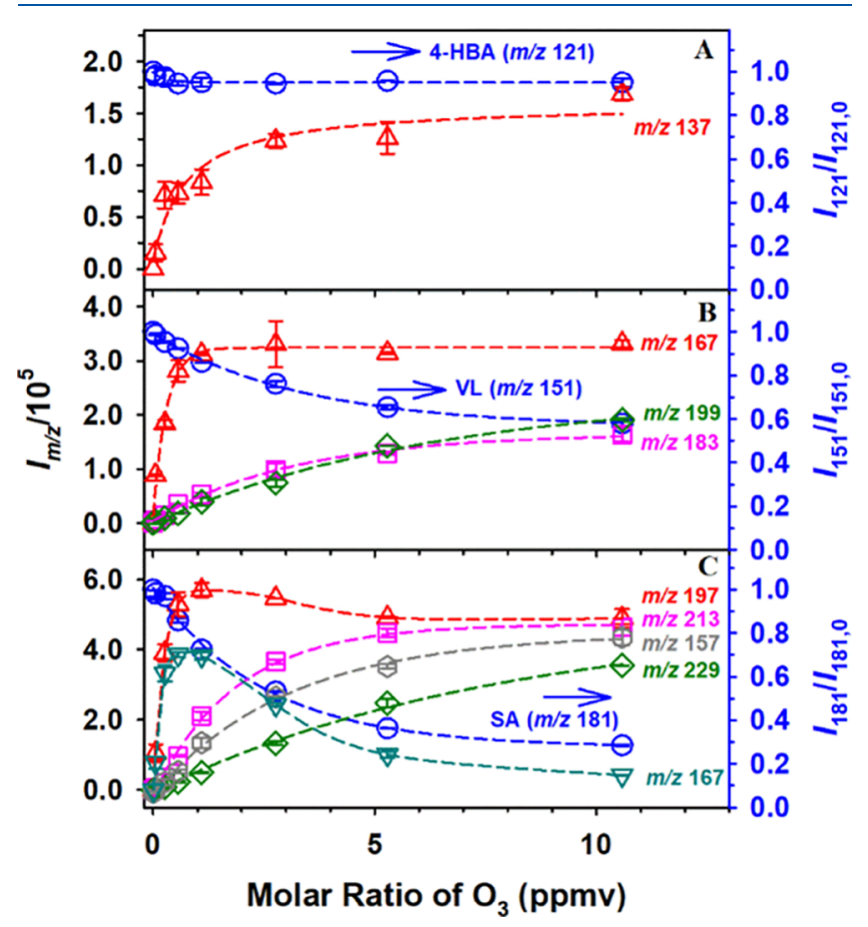

Figure 4. Normalized ion count (right axes) at $\mathrm{pH} 8.0$ of (A) 4-HBA $(\mathrm{m} / z$ 121), (B) VL $(m / z 151)$, and (C) SA $(m / z 181)$ relative to their values before $\mathrm{O}_{3}(\mathrm{~g})$ addition, $I_{m / z} I_{m / z, 0}$, for molar ratios of $\mathrm{O}_{3}$ from $55.0 \mathrm{ppbv}$ to $10.6 \mathrm{ppmv}$ during experiments at $\mathrm{pH}$ 8.0. The respective (left axes) ion count, $I_{m / z}$ of oxidation products is shown for (A) 4-hydroxybenzoic acid $(\mathrm{m} / z$ 137); (B) 5-hydroxyvanillin $(\mathrm{m} /$ $z$ 167), 2,5-dihydroxyvanillin $(m / z 183)$, and 2,5,6-trihydroxyvanillin $(\mathrm{m} / z$ 199); and (C) 2-hydroxysyringaldehyde $(\mathrm{m} / z$ 197), 2,6dihydroxysyringaldehyde $(\mathrm{m} / z$ 213), 2,6-dihydroxysyringic acid $(\mathrm{m} /$ $z$ 229), 5-hydroxyvanillin $(\mathrm{m} / z \mathrm{167})$, and 2-hydroxymuconic acid $(\mathrm{m} /$ $z$ 157). 
Figures $1-3$, varies with increasing molar ratios of $\mathrm{O}_{3}$. The ion counts for the three phenolic aldehyde reactants relative to their value in the absence of $\mathrm{O}_{3}(\mathrm{~g}), I_{m / z} I_{m / z, 0}$, decrease exponentially for $I_{181}>I_{151}>I_{121}$, as shown in Figure 4, indicating the oxidation reactivity trend growths with the number of $-\mathrm{OCH}_{3}$ substituents in the order 4-HBA $<\mathrm{VL}<$ $\mathrm{SA}$. Additional electron-donating $-\mathrm{OCH}_{3}$ groups decrease the redox potential, making the oxidation of the aromatic molecules thermodynamically more favorable. ${ }^{50}$ This predicted reactivity enhancement agrees well with the measured electron transfer potentials for 4-HBA, VL, and SA upon reacting with $\mathrm{O}_{3}(\mathrm{~g})$, which are discussed later.

Complete dissolution of $\mathrm{O}_{3}(\mathrm{~g})$ occurs on the outermost nanometer thin interfacial slab of the microdroplets. Diffusioncontrolled limitations can be neglected in this fast flow-through setup based on the behavior of the parent ions for increasing $\left[\mathrm{O}_{3}(\mathrm{~g})\right]$. The phenolic aldehydes display ion counts $\left(I_{121} / I_{121,0}\right.$, $I_{151} / I_{151,0}$, and $\left.I_{181} / I_{181,0}\right)$ that approach a steady state for increasing $\left[\mathrm{O}_{3}(\mathrm{~g})\right]$, as shown in Figure 4. Therefore, the phenolic aldehydes continuously diffuse from the core of the microdroplets to the nanometer-sized interface in nanoseconds, which is faster than $\tau_{\mathrm{c}}=1 \mu \mathrm{s}$, and continuously replenish the reagent after it gets oxidized. ${ }^{20,21,24}$

Panel (A) of Figure 4 for 4-HBA $(m / z 121)$ shows that $I_{137}$ for syringic acid, the only hydroxylated product, increases at higher $\mathrm{O}_{3}(\mathrm{~g})$ levels. Similarly, in panels $(\mathrm{B})$ and $(\mathrm{C})$ of Figure 4, $I_{167}$ and $I_{197}$ representing the respective first hydroxylation products of $\mathrm{VL}(\mathrm{m} / z 151)$ and $\mathrm{SA}(\mathrm{m} / z$ 181) reach a maximum at $\sim 1$ ppmv $\mathrm{O}_{3}(\mathrm{~g})$. At higher $\mathrm{O}_{3}(\mathrm{~g})$ levels, both $I_{167}$ and $I_{197}$ level off or start to decay at $\sim 2.5 \mathrm{ppmv} \mathrm{O}_{3}(\mathrm{~g})$ because of secondary oxidation, eventually reaching a steady-state condition. For example, an increase in second and third oxidation products is registered for VL by $I_{183}$ and $I_{199}$ (panel B) and for SA by $I_{213}$ and $I_{229}$ (panel C). In addition, the fast development of $I_{157}$ on higher exposure of SA to $\mathrm{O}_{3}(\mathrm{~g})$ (panel C) indicates that the production of 2-hydroxymuconic acid from the ring fragmentation after oxidative demethoxylation ${ }^{48}$ is favored. The comparable values for $I_{197}, I_{213}$, and $I_{157}$ from SA oxidation suggest that hydroxylation and ring fragmentation are both competitive oxidation channels. Similarly, the appearance of $I_{167}$ reaches a maximum at $\sim 1.0 \mathrm{ppmv} \mathrm{O}_{3}(\mathrm{~g})$ (panel C) and then decays as an intermediate in further reactions.

Figure 5 displays the change in $I_{m / z}$ values for the same species shown in Figure 4 during OESI-MS oxidation experiments of $50.0 \mu \mathrm{M}$ (A) 4-HBA, (B) VL, or (C) SA solutions for the $\mathrm{pH}$ range from 5.0 to 10.0 at constant 5016 ppbv $\mathrm{O}_{3}(\mathrm{~g})$. The $\mathrm{pH}$ range from 5.0 to 10.0 can be used in practical applications to cover the speciation of the three phenolic aldehydes studied, from fully protonated to fully dissociated species. In the context of atmospheric measurements, the experiments at $\mathrm{pH} 5.0$ fall within the upper end of the $\mathrm{pH}$ occurrences for fine aerosol $(0.8 \leq \mathrm{pH} \leq 5.5) .{ }^{51}$ The experiments between $\mathrm{pH} 5.0$ and 7.0 also represent well the center of the range occurring in cloud water $(2.6 \leq \mathrm{pH} \leq$ 7.2). ${ }^{51}$ Finally, the experiments between $\mathrm{pH} 7.0$ and 10.0 can represent aerosol with a diameter of $<2.5 \mu \mathrm{m}\left(\mathrm{PM}_{2.5}\right)$ present over agricultural regions, ${ }^{52,53}$ where anthropogenic biomass burning emissions often coincide with increased ammonia emissions from fertilizers and livestock. ${ }^{31,54}$ Therefore, the experimental $\mathrm{pH}$ range outlines a set of true atmospheric conditions.

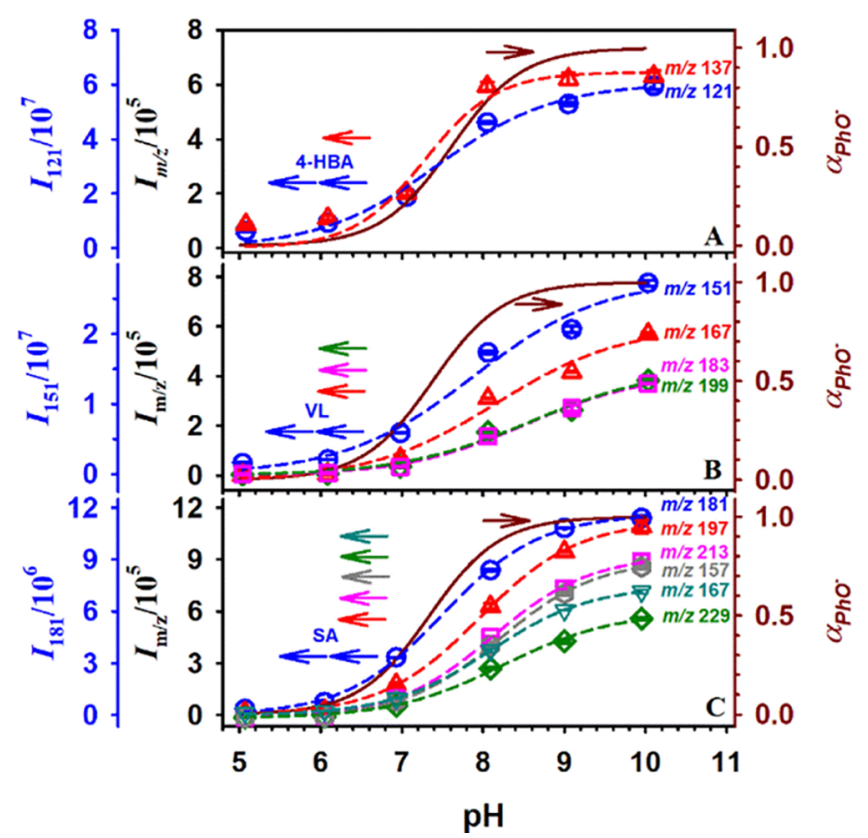

Figure 5. Ion counts, $I_{m / z}$ vs $\mathrm{pH}$ during experiments with $5016 \mathrm{ppbv}$ $\mathrm{O}_{3}(\mathrm{~g})$ for (A) 4-HBA $(\mathrm{m} / \mathrm{z} 121)$ and 4-hydroxybenzoic acid $(\mathrm{m} / \mathrm{z}$ 137); (B) VL $(m / z \quad 151)$, 5-hydroxyvanillin $(m / z \quad 167)$, 2,5dihydroxyvanillin $(m / z 183)$, and 2,5,6-trihydroxyvanillin $(\mathrm{m} / z$ $199)$; and (C) SA ( $m / z 181)$, 2-hydroxysyringaldehdye $(\mathrm{m} / z$ 197), 2,6-dihydroxysyringaldehyde $(m / z 213)$, 2,6-dihydroxysyringic acid $(m / z 229)$, 5-hydroxyvanillin $(m / z 167)$, and 2-hydroxymuconic acid $(m / z$ 157). The dashed lines display sigmoid fittings of the data. The right axes show (brown solid line) the calculated fraction of dissociation for the reactant phenolic aldehydes versus $\mathrm{pH}$.

As expected, the ion count for all species, as shown in Figure 5 , increases for higher $\mathrm{pH}$, following a dependence controlled by the acid/base equilibrium of the phenolic group coming from the bulk solvent in this $\mathrm{pH}$ range. ${ }^{41,55,56}$ Importantly, the data profiles for the three reactants, as shown in Figure 5, are fitted with sigmoid curves that resemble (within experimental error) the speciation of the phenolic aldehyde reactants. Furthermore, the profiles for the products, as shown in Figure 5 , have inflexion points that are progressively shifted toward higher $\mathrm{pH}$ values (with the exception of $I_{137}$ ) relative to the reactants. Because (1) the loss of 4-HBA after exposure to $\mathrm{O}_{3}(\mathrm{~g})$, as shown in panel (A) of Figure 5, is low (typically $\sim 5 \%)$, (2) there is no consecutive reactions of the products at $\mathrm{m} / z$ 137, and (3) the inflexion point of the sigmoid curve versus $\mathrm{pH}$ for the product is shifted to the left of the reactant at $m / z 121$ (and $\mathrm{pK}_{\mathrm{a} 4-\mathrm{HBA}}$ ), it is possible to conclude that the more acidic product is 4-hydroxybenzoic acid. Indeed, the progressive shifting of the inflexion points of products toward higher $\mathrm{pH}$ values, as shown in panels (B) and (C) of Figure 5, suggests that consecutive hydroxylation of the aromatic ring occurs first for VL and SA before the carbonyl is converted into a carboxylic acid and fragmentation is possible for the products at $\mathrm{m} / z 157$ to be observed.

The strong $\mathrm{pH}$ dependence for the oxidations, as shown in Figure 5, is in agreement with the related bulk ozonolysis studies of VL and SA in a stopped-flow reactor, which showed that rates increase exponentially before reaching a plateau in the $\mathrm{pH}$ range $7-8 .^{57}$ The redox potential of phenolic compounds decreases linearly with increasing $\mathrm{pH},{ }^{50}$ favoring electron transfer between phenolic aldehydes and ozone and 
Table 1. Physical Constants of 4-HBA, VL, and SA

\begin{tabular}{|c|c|c|c|c|c|c|c|c|c|c|c|}
\hline name & MW (amu) & $\mathrm{p} K_{\mathrm{a}}^{a}$ & $\mathrm{pH}$ & $\alpha_{\mathrm{PhOH}}$ & $\alpha_{\mathrm{PhO}^{-}}$ & $E_{\text {red,1 }}(\mathrm{V})^{b}$ & $E_{\mathrm{red}, 2}(\mathrm{~V})^{c}$ & $\Delta E_{1}(\mathrm{~V})^{d}$ & $\Delta E_{2}(\mathrm{~V})^{e}$ & $\left.\Delta G_{1}(\mathrm{~kJ} \mathrm{~mol})^{-1}\right)^{f}$ & $\Delta G_{2}\left(\mathrm{~kJ} \mathrm{~mol}{ }^{-1}\right)^{f}$ \\
\hline \multirow[t]{6}{*}{ 4-HBA } & 122.12 & 7.61 & 4.98 & 0.998 & 0.002 & 1.136 & & -0.126 & & 12.16 & \\
\hline & & & 6.01 & 0.975 & 0.025 & 1.133 & & -0.123 & & 11.87 & \\
\hline & & & 7.04 & 0.788 & 0.212 & 1.119 & 0.884 & -0.109 & 0.126 & 10.52 & -12.16 \\
\hline & & & 8.03 & 0.275 & 0.725 & 1.091 & 0.856 & -0.081 & 0.154 & 7.82 & -14.86 \\
\hline & & & 9.04 & 0.036 & 0.964 & 1.086 & 0.843 & -0.076 & 0.167 & 7.33 & -16.11 \\
\hline & & & 10.04 & 0.004 & 0.996 & 1.097 & 0.823 & -0.087 & 0.187 & 8.39 & -18.04 \\
\hline \multirow[t]{6}{*}{ VL } & 152.15 & 7.38 & 4.98 & 0.996 & 0.004 & 0.902 & & 0.108 & & -10.42 & \\
\hline & & & 6.01 & 0.959 & 0.041 & 0.899 & & 0.111 & & -10.71 & \\
\hline & & & 7.04 & 0.686 & 0.314 & 0.883 & 0.669 & 0.127 & 0.341 & -12.25 & -32.90 \\
\hline & & & 8.03 & 0.183 & 0.817 & 0.869 & 0.684 & 0.141 & 0.326 & -13.60 & -31.45 \\
\hline & & & 9.04 & 0.021 & 0.979 & 0.871 & 0.672 & 0.139 & 0.338 & -13.41 & -32.61 \\
\hline & & & 10.04 & 0.002 & 0.998 & 0.875 & 0.652 & 0.135 & 0.358 & -13.03 & -34.54 \\
\hline \multirow[t]{6}{*}{ SA } & 182.17 & 7.34 & 4.98 & 0.996 & 0.004 & 0.848 & & 0.162 & & -15.63 & \\
\hline & & & 6.01 & 0.955 & 0.045 & 0.848 & & 0.162 & & -15.63 & \\
\hline & & & 7.04 & 0.666 & 0.334 & 0.847 & 0.633 & 0.163 & 0.377 & -15.73 & -36.37 \\
\hline & & & 8.03 & 0.170 & 0.830 & 0.872 & 0.623 & 0.138 & 0.387 & -13.31 & -37.34 \\
\hline & & & 9.04 & 0.020 & 0.980 & 0.886 & 0.621 & 0.124 & 0.389 & -11.96 & -37.53 \\
\hline & & & 10.04 & 0.002 & 0.998 & 0.89 & 0.618 & 0.12 & 0.392 & -11.58 & -37.82 \\
\hline
\end{tabular}

${ }^{a}$ Experimental values. ${ }^{44,46,47}{ }^{b}$ For $\mathrm{PhO} \% / \mathrm{PhO}^{-}$(reaction $\mathrm{R} 1$ in Scheme 2 ). ${ }^{c} \mathrm{PhOH}^{\bullet+} / \mathrm{PhOH}$ (reaction R2 in Scheme 2) measured with Ag/AgCl at the given $\mathrm{pH}$ (Table S1, Supporting Information) and converted to standard hydrogen electrode (SHE) using the equation $E_{\text {red }}(\mathrm{SHE})=E_{\text {red }}(\mathrm{Ag} /$ $\mathrm{AgCl}$ sat. $\mathrm{KCl})+0.197 .{ }^{64}{ }^{d} \Delta E_{1}=E_{\mathrm{O}_{3} / \mathrm{O}_{3}^{--}}-E_{\mathrm{PhO} 0^{*+} / \mathrm{PhOH}} \cdot{ }^{e} \Delta E_{2}=E_{\mathrm{O}_{3} / \mathrm{O}_{3}^{--}}-E_{\mathrm{PhO}^{\circ} / \mathrm{PhO}^{-}}$, with $E_{\mathrm{O}_{3} / \mathrm{O}_{3}^{*-}}=1.01 \mathrm{~V} .{ }^{65} f_{\Delta G}=-n F \Delta E$ with $n=1$ and $F=96.485 \mathrm{~kJ} \mathrm{~mol}^{-1} \mathrm{~V}^{-1}$.

resulting in an enhanced reactivity at higher $\mathrm{pH}$. In addition, competing photochemical processes should proceed with the participation of the reactive enol tautomer at high $\mathrm{pH}$ (when $\mathrm{pH}>\mathrm{p} K_{\mathrm{a}}$ values, as shown in Table 1). ${ }^{58}$

The results mentioned above for the oxidation experiments on the surface of water indicate that the reactivity of phenolic aldehydes increases in the order 4-HBA $<$ VL $<$ SA. The comparative reactivity trend recorded by OESI-MS can be explained by the electron density donation effect added to 4HBA by one or two extra methoxy $\left(-\mathrm{OCH}_{3}\right)$ substituents. The increase in electron density of the aromatic ring by each additional $-\mathrm{OCH}_{3}$ group makes the reactant more susceptible toward electrophilic attack by ozone. ${ }^{59-61}$ The two reactivity channels observed correspond to oxidation pathways from in situ generated $\mathrm{HO}^{\bullet}$ and direct ring fragmentation by $\mathrm{O}_{3}{ }^{20,21}$ These pathways are discussed in detail below.

Oxidative Functionalization of the Aromatic Rings by HO. Scheme 2 presents an integrated reaction mechanism for the oxidation of the three phenolic aldehydes studied by in situ generated $\mathrm{HO}^{\bullet}$ radicals. ${ }^{20}$ All reactions mentioned in the reaction schemes below are numbered consecutively. A key step for in situ production of $\mathrm{HO}^{\bullet}$ is the electron transfer between phenolic aldehydes and dissolved $\mathrm{O}_{3}$ (reactions $\mathrm{R} 1$ and $\mathrm{R} 2$ in Scheme 2). An ozonide radical anion $\left(\mathrm{O}_{3}^{--}\right)$is formed in reaction $\mathrm{R} 1$ together with the phenoxyl radical, which can also be formed from the phenol radical cation undergoing ultrafast deprotonation. ${ }^{20,21,62,63}$

As a working example, the determined first and second redox potentials of SA at $\mathrm{pH} 8.03$ (Supporting Information), $E_{\text {red, } 1}=$ $0.872 \mathrm{~V}$ and $E_{\text {red,2 }}=0.623 \mathrm{~V}$ (Table 1), respectively, and that of ozone, $E_{\mathrm{O}_{3}}=1.01 \mathrm{~V}$ (at $\mathrm{pH} 7.0$ ), indicate thermodynamically favorable $\Delta E_{2}=+0.385 \mathrm{~V}$ and $\Delta E_{1}=+0.138 \mathrm{~V}$ for electron transfer reactions R1 and R2, respectively. For the same example at $\mathrm{pH} 8.03$, Table 1 also shows the calculated free energy change for reactions R1 and R2 of SA with ozone, $\Delta G_{2}=-13.4 \mathrm{~kJ} \mathrm{~mol}^{-1}$ and $\Delta G_{1}=-37.4 \mathrm{~kJ} \mathrm{~mol}^{-1}$, respectively. Overall, Table 1 lists the experimental $\Delta E$ and
$\Delta G$ values for the $\mathrm{pH}$ range from 5 to 10 of 4-HBA, VL, and $\mathrm{SA}$, together with the physical constants and dissociation fractions of the three compounds at a given $\mathrm{pH}$. A comparison of $\Delta G_{1}$ and $\Delta G_{2}$ values for each of the three compounds shows a larger tendency to undergo electron transfer with ozone for the phenoxide anion (reaction R1) rather than for the cation radical (reaction $\mathrm{R} 2$ ) at $\mathrm{pH} \geq 7.0$. Instead, at $\mathrm{pH} \leq 6.0$, as the fraction of phenol $\alpha_{\mathrm{PhOH}} \rightarrow 1$ for $\mathrm{VL}$ and SA, the only possibility left for electron transfer of these compounds implies the participation of their cation radicals (reaction R2 in Scheme 2), which is thermodynamically prevented for 4-HBA.

Equilibrium R3 with $K_{\text {eq }}=5.5 \times 10^{-7} \mathrm{M}$ at $20{ }^{\circ} \mathrm{C}$ indicates that $\mathrm{O}_{3}^{\bullet-}$ coexists with the strong base $\mathrm{O}^{\bullet-}\left(\mathrm{p} K_{\mathrm{a}}=11.8\right)$ which, under relevant environmental (and the experimental conditions here), is converted immediately by reaction $\mathrm{R} 4$ into its conjugated acid $\mathrm{HO}^{\bullet} .{ }^{61,66}$ This in situ generated $\mathrm{HO}$ can play a crucial role in the degradation of organic compounds on atmospheric interfaces and provide useful information about the reactivity of the oxidizer, independent of its source and mechanism of formation. ${ }^{20,21,63,67,68}$ Once generated, $\mathrm{HO}^{\bullet}$ attacks (i.e., in reaction R5) the activated positions (rich in electron density from the donating substituents $-\mathrm{OH}$ and/or $\left.-\mathrm{OCH}_{3}\right)$, producing a cyclohexadienyl radical that adds up molecular oxygen $\left(\mathrm{O}_{2}\right)$ through reaction R6. ${ }^{60,61}$ The cyclohexadienyl peroxy radical generated eliminates hydroperoxyl radicals $\left(\mathrm{HO}_{2}^{\circ}\right)$ as part of reaction $\mathrm{R} 6$, producing a firstgeneration hydroxylated product after rearrangement. Although less likely in our system due to the low probability of detecting the encounter among two radicals, the phenoxyl radical has been proposed to also react directly with $\mathrm{HO}^{\bullet}$ to produce the corresponding hydroxylated product. ${ }^{69}$

The ortho $\mathrm{HO}^{\circ}$ attack to the three phenolic aldehyde molecular probes creates cyclohexadienyl radicals in reaction $\mathrm{R} 5$ (Scheme 2). The cyclohexadienyl radicals react with $\mathrm{O}_{2}$ at a rate controlled by diffusion (e.g., for MPs $\left.2 \times 10^{9} \mathrm{M}^{-1} \mathrm{~s}^{-1}\right)^{68}$ and eliminate a hydroperoxyl radical in reaction $\mathrm{R} 6$ to form hydroxylated products. This kind of functionalization reaction 
Scheme 2. Proposed Oxidation Mechanism of (Blue Font) 4-HBA, (Pink Font) VL, and (Green Font) SA by Hydroxyl Radicals on the Surface of Water ${ }^{a, b}$

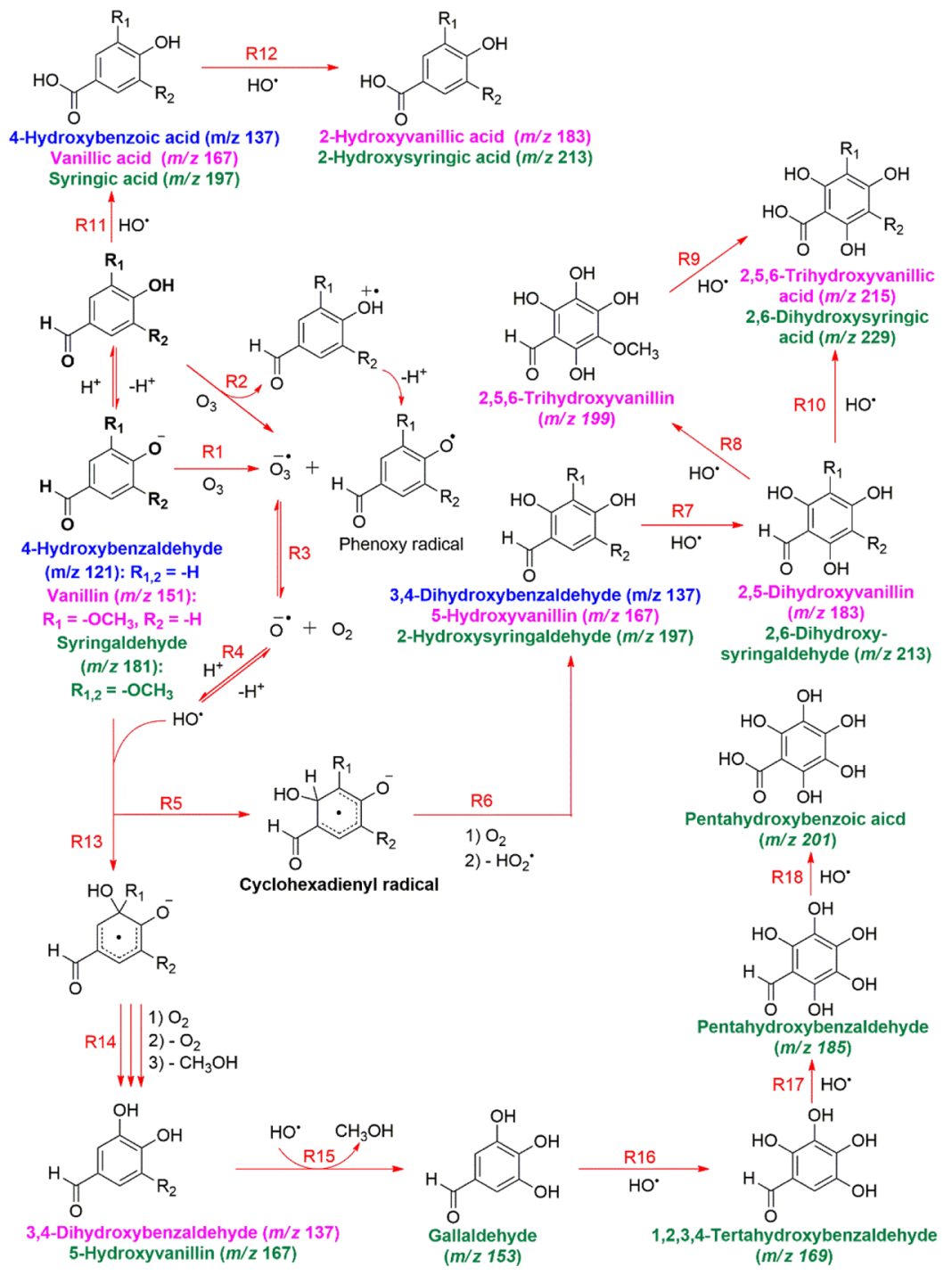

${ }^{a}$ Reaction numbers are given in red font. ${ }^{b}$ Observed products and $m / z$ values are given in the same color of the precursor.

was observed on the surface of water for a series of substituted catechols. $^{20,21}$ For VL (precursor and products in purple font in Scheme 2), the consecutive hydroxylation by reactions R5 to R10 produces 5-hydroxyvanillin $(\mathrm{m} / z \mathrm{167}), 2,5$-dihydroxyvanillin $(m / z \quad 183), 2,5,6$-trihydroxyvanillin $(m / z 199)$, and finally 2,5,6-trihydroxyvaleric acid $(m / z 215)$. Similarly, for SA (precursor and products in green font in Scheme 2), hydroxylation reactions produce 2-hydroxysyringaldehyde ( $m / z$ 197), 2,6-dihydroxysyringaldehyde $(m / z 213)$, and 2,6dihydroxysyringic acid $(m / z 229)$. The related ring hydroxylation product of 4-HBA (precursor and product in blue font in Scheme 2) would be 3,4-HBA $(\mathrm{m} / z$ 137), which is depicted in Scheme 2, but not believed to be efficiently formed in the microsecond contact time. Instead, $>\mathrm{C}=\mathrm{O}$ side chain oxidation into $-\mathrm{COOH}$ by reaction $\mathrm{R} 11$ converts 4-HBA, $\mathrm{VL}$, and SA into 4-hydroxybenzoic acid $(\mathrm{m} / z$ 137), vanillic acid $(m / z 167)$, and syringic acid $(m / z 197)$, respectively. ${ }^{45}$ In addition, 5-hydroxyvanillin and 2-hydroxysyringaldehyde can be converted (reaction R12) into 2-hydroxyvanillic acid $(\mathrm{m} / z$ $183)$ and 2-hydroxysyringic acid $(m / z 213)$, respectively.
MPs can also undergo oxidative demethoxylation reaction $\mathrm{R} 13$ by $\mathrm{HO}^{\bullet}$ attack to form ipso adducts. There is a low probability in this study for the ipso adducts to eliminate $\mathrm{CH}_{3} \mathrm{OH}$ directly to produce semiquinone radicals, a reaction that would require anoxic conditions. ${ }^{48,68}$ Instead, the ipso adduct radicals undergo a complex multistep process (not shown in Scheme 2), symbolized by reaction R14, to incorporate $\mathrm{O}_{2}$ forming peroxyl radicals, lose $\mathrm{O}_{2}$ to form cyclohexadienyl products, and eliminate $\mathrm{CH}_{3} \mathrm{OH}$ to produce 3,4-dihydroxybenzaldehyde $(\mathrm{m} / z$ 137), 5-hydroxyvanillin $(\mathrm{m} / z$ $167)$, and consecutively, by an analogous reaction $\mathrm{R} 15$, gallaldehyde $(m / z 153)$. Once gallaldehyde is produced, its further hydroxylation generates 1,2,3,4-tetrahydroxybenzladehyde $(m / z 169)$, pentahydroxybenzaldehyde $(m / z 185)$, and pentahydroxybenzoic acid $(m / z 201)$ by reactions R16, R17, and R18, respectively. ${ }^{20,21}$

Fragmentation of the Aromatic Rings by $\mathrm{O}_{3}$. Scheme 3 shows the proposed ring-opening fragmentation reactions for VL and SA. VL, SA, and their hydroxylation products react with $\mathrm{O}_{3}(\mathrm{~g})$ forming primary ozonides, which then rearrange as Criegee intermediates ${ }^{70,71}$ and react with water to form 
Scheme 3. Proposed Ring-Opening Oxidation Reactions of VL, SA, and Some of their Hydroxylation Products by Ozone on the Surface of Water ${ }^{a, b}$

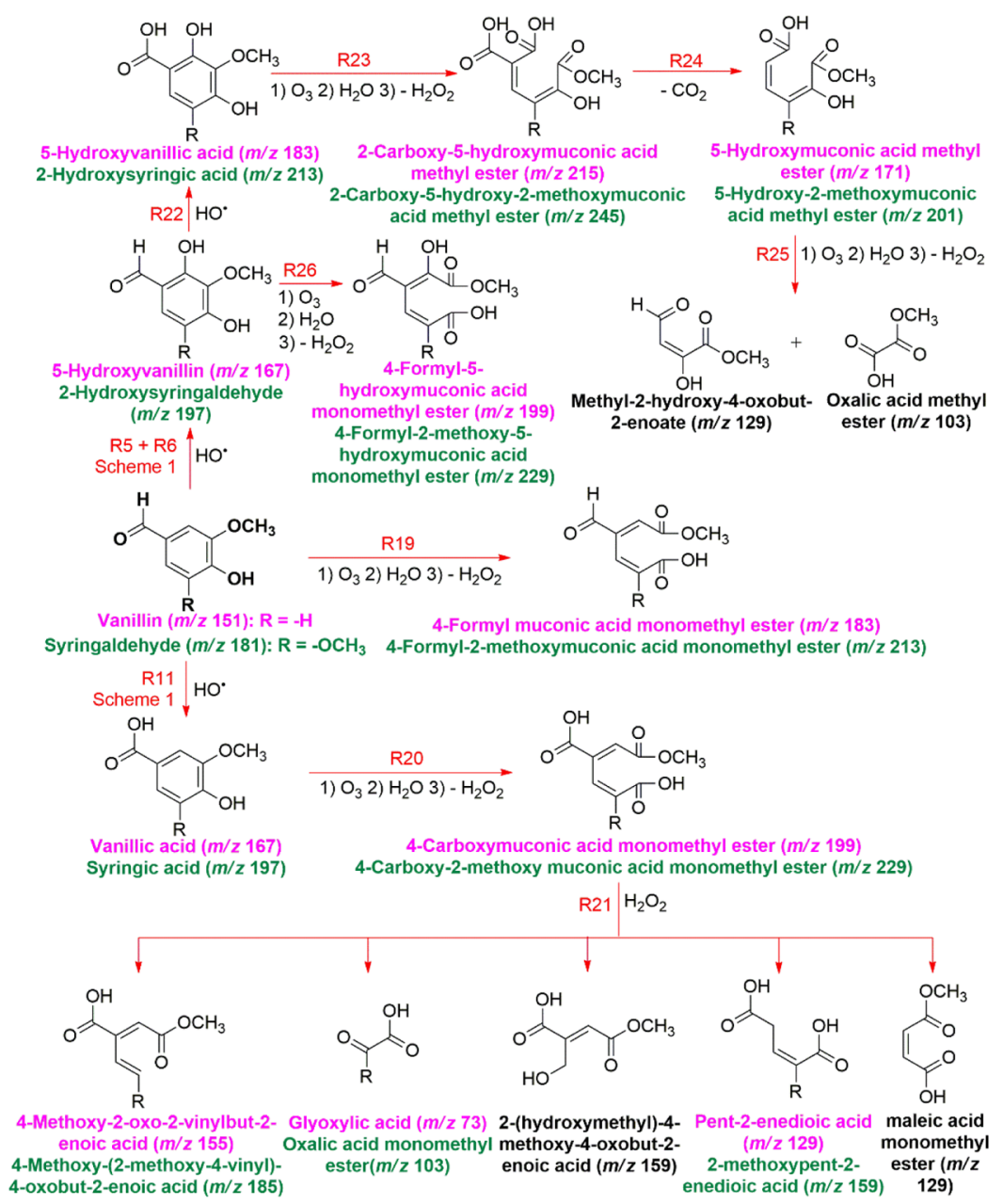

${ }^{a}$ Reaction numbers are given in red font. ${ }^{b}$ Observed products and $m / z$ values are given in the same color of the precursor.

Scheme 4. Proposed Ring-Opening Oxidation Reactions of the Selected Hydroxylation Products by Ozone on the Surface of Water $^{a, b}$

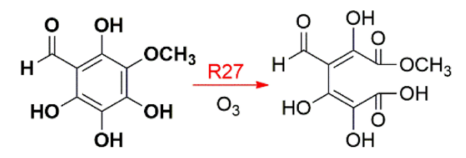$$
\text { 2,5,6-Trihydroxyvanillin 4-Formyl-2,3,5- }
$$$$
\left(\mathrm{m} / \mathrm{z}^{199)} \quad\right. \text { trihydroxymuconic acid }
$$

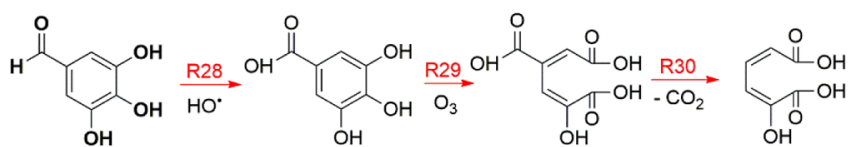

Gallaldehyde ( $m / z$ 153) Gallic acid $(\mathrm{m} / \mathrm{z} 169) \quad \begin{gathered}\text { 3-Carboxy-5-hydroxy } \\ \text { muconic acid }(\mathrm{m} / \mathrm{z} 201)\end{gathered} \begin{gathered}2 \text {-Hydroxymuconic acid } \\ (\mathrm{m} / \mathrm{z} 157)\end{gathered}$
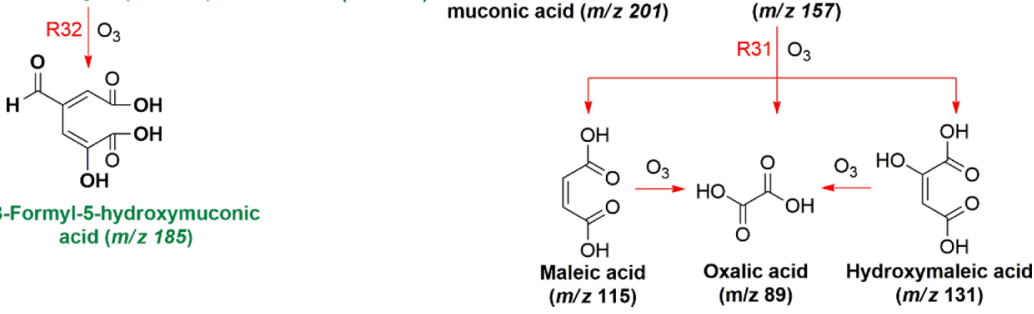

${ }^{a}$ Reaction numbers are given in red font. ${ }^{b}$ Observed products are indicated by their $m / z$ values. 
hydroperoxide intermediates that decompose, eliminating $\mathrm{H}_{2} \mathrm{O}_{2},{ }^{72}$ into dicarboxylic acid monomethyl esters, as displayed in Scheme 3. For example, reaction R19 (Scheme 3) shows that VL and SA generate 4-formyl muconic acid monomethyl ester $(m / z 183)$ and 4-formyl-2-methoxymuconic acid monomethyl ester $(m / z 213)$, respectively. The previous process can occur also for vanillic and syringic acids (products of reaction R11 in Scheme 2) to form 4-carboxymuconic acid monomethyl ester $(m / z 199)$ and 4-carboxy-2-methoxymuconic acid monomethyl ester $(m / z 229)$ in reaction R20 (Scheme 3), respectively.

The previous products derived from VL and SA can undergo Baeyer-Villiger oxidation ${ }^{73}$ with in situ formed $\mathrm{H}_{2} \mathrm{O}_{2}$ in reaction R21 (Scheme 3) to produce 4-methoxy-2-oxo-2vinylbut-2-enoic acid $(\mathrm{m} / z \mathrm{155})$ and 4-methoxy-(2-methoxy-4vinyl)-4-oxobut-2-enoic acid $(\mathrm{m} / \mathrm{z} 185)$, pent-2-enedioic acid $(m / z 129)$ and 2-methoxypent-2-enedioic acid $(\mathrm{m} / z$ 159), glyoxylic acid $(\mathrm{m} / z 73)$ and oxalic acid monomethyl ester $(\mathrm{m} /$ $z$ 103), respectively, among other common products such as 2(hydroxymethyl)-4-methoxy-4-oxobut-2-enoic acid $(m / z 159)$, maleic acid monomethyl ester $(m / z 129)$, and formic acid $(m /$ $z 45)$.

Scheme 3 also includes examples of additional reactions for the products 5-hydroxyvanillic acid $(m / z \quad 183)$ and 2hydroxysyringic acid $(\mathrm{m} / z$ 213) from the hydroxylation sequence R5 + R6 + R22, respectively forming 2-carboxy-5hydroxymuconic acid methyl ester $(m / z 215)$ and 2-carboxy-5hydroxy-2-methoxymuconic acid methyl ester $(m / z 245)$ after aromatic ring cleavage. The previous $\alpha, \beta$-unsaturated carboxylic acid monomethyl esters could undergo decarboxylation reaction R24, producing 5-hydroxymuconic acid methyl ester $(\mathrm{m} / z$ 171) and 5-hydroxy-2-methoxymuconic acid methyl ester $(m / z 201)$. Direct ozonolysis in reaction R25 (Scheme 3) could also explain the production of methyl-2-hydroxy-4oxobut-2-enoate $(\mathrm{m} / z 129)$ and oxalic acid methyl ester $(\mathrm{m} / z$ 103). For instance, direct ozonolysis of 5-hydroxyvanillin $(\mathrm{m} / z$ $167)$ and 2-hydroxysyringaldehyde $(\mathrm{m} / z$ 197) in reaction R26 (Scheme 3) results in the production of 4-formyl-5hydroxymuconic acid monomethyl ester $(m / z$ 199) and 4formyl-2-methoxy-5-hydroxymuconic acid monomethyl ester $(\mathrm{m} / z$ 229), respectively. Because no MS peaks other than $\mathrm{m} / \mathrm{z}$ 137 are observed for the oxidation of 4-HBA $(m / z 121)$, this molecule did not undergo ring-opening ozonolysis at the microsecond contact time of the experiments.

Scheme 4 displays some final examples of ring cleavage products $^{74}$ from 2,5,6-trihydroxyvanillin $(m / z$ 199) and gallaldehyde $(m / z 153)$ generated in reactions $\mathrm{R} 8$ and $\mathrm{R} 15$ of Scheme 2, respectively. The former generates 4-formyl2,3,5-trihydroxymuconic acid monomethyl ester $(\mathrm{m} / z$ 231) in reaction R27 (Scheme 4), and the latter after hydroxylation into gallic acid (reaction R28) produces in reaction R29 3carboxy-5-hydroxymuconic acid $(\mathrm{m} / z$ 201). Decarboxylation in reaction R30 results in 2-hydroxymuconic acid $(\mathrm{m} / z$ 157), which can be further oxidized by reaction R31 into smaller species such as oxalic acid $(m / z 89)$, maleic acid $(m / z 115)$, and hydroxymaleic acid $(m / z 131)$. The ring cleavage of gallaldehyde in reaction R32 explains the formation of 3formyl-5-hydroxymuconic acid $(m / z 185)$.

\section{CONCLUSIONS AND ATMOSPHERIC} IMPLICATIONS

This study reveals how interfacial reactions of two MPs among three phenolic aldehydes present in biomass burning emissions contribute to increase the oxygenated fraction of organic compounds in brown carbon species found in SOA. The observed oxidation of phenolic aldehydes on the surface of water proceeds mainly through hydroxylation (Scheme 2) as well as by aromatic ring cleavage (Schemes 3 and 4) in the $\mathrm{pH}$ range investigated. ${ }^{20,21}$ The key step to initiate hydroxylation reactions on the surface of water involves electron transfer reactions $\mathrm{R} 1$ and $\mathrm{R} 2$. These results demonstrate that $\mathrm{O}_{3}(\mathrm{~g})$ levels as low as 45-66 ppbv can break the aromatic ring and also induce the formation of $\mathrm{HO}^{\bullet}$ radicals, as determined by the products detected in our atmospheric pressure ionization technique. Cyclic voltammetry measurements support the interpretation that at $\mathrm{pH} \leq 10.8$, the formed conjugate base $\mathrm{O}^{\bullet-}\left(\mathrm{p} K_{\mathrm{a}}=11.8\right){ }^{66}$ from the favorable electron transfers from the acid/base pair, determined in Table 1 by $\Delta G_{1}$ and $\Delta G_{2}$, becomes fully protonated. Furthermore, the results at $\mathrm{pH} 5$ for the fully undissociated species should be valid down to $\mathrm{pH} 1$, as for both cases, the undissociated fraction $\alpha_{\mathrm{PhOH}} \rightarrow 1$.

OESI-MS experiments revealed the oxidative pathways for three phenolic aldehydes, and the careful interpretation of the data sets enabled inferring the reactive centers for proposing consecutive $\mathrm{HO}^{\circ}$ - and $\mathrm{O}_{3}$-driven reactions. The generation of hydroxyl-substituted aromatics generally preceded the formation of aromatic and aliphatic carboxylic acids. Future works should compare the reaction products (1) between bulk and surface studies and (2) at longer exposures with those from direct photochemistry that generate intermediates with humiclike fluorescence properties that can be structurally related to the formation of dimer and trimer species by self-reaction of phenoxyl radicals or cross-reaction of phenoxyl and ketyl radicals. $^{30}$

Given the availability of information for VL, this molecule can be used to compare the competitive loss pathways of phenolic carbonyls among phases and reaction pathways. The aqueous photodegradation of VL under simulated sunlight irradiation proceeds with a lifetime of $\tau_{\mathrm{VL}+h \nu(\mathrm{aq})}=1.1-2.2$ $\mathrm{h}^{29,30}$ The rate constants of VL reacting with $\mathrm{HO}^{\bullet}$ in water at $\mathrm{pH} 5$ and 9 are $k_{\mathrm{VL}+\mathrm{HO}}{ }_{(\mathrm{aq}), 5}=3.3 \times 10^{9} \mathrm{M}^{-1} \mathrm{~s}^{-1}$ and $k_{\mathrm{VL}+\mathrm{HO}}{ }_{(\mathrm{aq}), 9}=6.6 \times 10^{9} \mathrm{M}^{-1} \mathrm{~s}^{-1}$, respectively. ${ }^{75}$ To estimate the lifetime of $\mathrm{VL}$ against loss by $\mathrm{HO}^{\circ}$ on the surface of water and in aqueous particles, the concentration of this radical is constrained by a low limit value $\left[\mathrm{HO}^{\bullet}(\mathrm{aq})\right]=7.5 \times 10^{-15}$ radicals $\mathrm{L}^{-1}$. $^{76}$ Therefore, the lifetimes of $\mathrm{VL}$ reacting with $\mathrm{HO}^{\circ}$ in water at $\mathrm{pH} 5$ and 9 are $\tau_{\mathrm{VL}+\mathrm{HO}}{ }_{(\mathrm{aq}), 5}=7.8 \mathrm{~h}$ and $\tau_{\mathrm{VL}+\mathrm{HO}}{ }_{(\mathrm{aq}), 9}=3.9 \mathrm{~h}$, respectively. Instead, the corresponding lifetime of VL on the surface of water is affected by the larger in situ produced $\mathrm{HO}^{\circ}$ on the surface of water. From a previous air-water interface study with substituted catechols, and after scaling down the oxidizer level to $50 \mathrm{ppbv}$, an upper limit for the in situ generated $\left[\mathrm{HO}^{\circ}\right]_{\text {interface }}=2.0( \pm 0.5) \times 10^{-12}$ radicals $\mathrm{L}^{-1}$ is obtained. In consequence, the interfacial oxidation of VL should proceed with much shorter lifetimes $\tau_{\mathrm{VL}+\mathrm{HO}}{ }^{\circ}$ (interface),5$=105 \mathrm{~s}$ and $\tau_{\mathrm{VL}+\mathrm{HO}}{ }^{\circ}$ (interface), $9=53 \mathrm{~s}$, resulting in the major loss channel. Considering the average rate constant for the reaction of MPs with $\mathrm{HO}^{\bullet}$ in the gas phase $\left(k_{\mathrm{MPs}+\mathrm{HO}}{ }^{\circ} \mathrm{g}\right)=6 \times 10^{-11} \mathrm{~cm}^{3}$ molecules $\left.^{-1} \mathrm{~s}^{-1}\right),{ }^{59}$ for an average tropospheric $\left[\mathrm{HO}^{\circ}\right]=1.6 \times 10^{6}$ radicals cm${ }^{-3}, 77$ the residence time in the gas phase for MPs is $\tau_{\mathrm{MPs}+\mathrm{HO}}{ }_{(\mathrm{g})}=2.9 \mathrm{~h}$, which is much larger than at the interface but comparable to that in water. In contrast, the atmospheric lifetime of the related MP 4-propylguaiacol reacting with $40 \mathrm{ppbv}_{3}(\mathrm{~g})$ on the surface of dry $\mathrm{NaCl}$ is $\tau_{{\mathrm{MPs}+\mathrm{O}_{3} \text { (ads.) }}}=28 \mathrm{~h},{ }^{74}$ which is even $\sim 10$ times 
longer than $\left.\tau_{\mathrm{MPs}_{\mathrm{HO}}}{ }^{\circ} \mathrm{g}\right)$. Thus, the $\mathrm{HO}^{\bullet}$-driven reactivity observed here at the air-water interface, despite the oxidizer origin, is expected to contribute significantly to the daytime loss of MPs on the surface of atmospheric aerosols and waters.

New heterogeneous processes, which have not been considered in atmospheric models before, show that ubiquitous MPs can generate precursors for SOA formation. The quickly produced water-soluble organic compounds by hydroxylation reactions are more likely to partition into the particle phase, where they can be further processed into aged species with different optical properties. ${ }^{20,21,43,78}$ In addition, the large $\mathrm{O} / \mathrm{C}$ ratio of the unsaturated dicarboxylic acids and related compounds produced from ozonolysis reactions suggests that the aged material is less volatile and more water soluble than its corresponding MP precursors. ${ }^{13,43,79}$ This combined effect may significantly alter the light scattering and absorption properties of oxidized SOA. ${ }^{12,19,25}$ Because the residence time of typical biomass burning aerosols against deposition is 1 week, future surface oxidation studies during longer timescales and variable environmental conditions should be useful to reveal the magnitude of absorption property changes. ${ }^{12,43}$

\section{ASSOCIATED CONTENT}

\section{(s) Supporting Information}

The Supporting Information is available free of charge at https://pubs.acs.org/doi/10.1021/acs.jpca.0c05944.

Control experiments, cyclic voltammograms at variable $\mathrm{pH}$, cyclic voltammetry processing to obtain their second derivative, methodology for inflection potential determination, and experimental redox potentials versus $\mathrm{Ag} / \mathrm{AgCl}$ reference electrode (PDF)

\section{AUTHOR INFORMATION}

\section{Corresponding Author}

Marcelo I. Guzman - Department of Chemistry, University of Kentucky, Lexington, Kentucky 40506, United States; 구이.org/0000-0002-6730-7766; Phone: (859)323-2892; Email: marcelo.guzman@uky.edu

\section{Author}

Md. Sohel Rana - Department of Chemistry, University of Kentucky, Lexington, Kentucky 40506, United States

Complete contact information is available at:

https://pubs.acs.org/10.1021/acs.jpca.0c05944

\section{Notes}

The authors declare no competing financial interest.

\section{ACKNOWLEDGMENTS}

M.I.G. acknowledges funding from the U.S.A. National Science Foundation under award 1903744.

\section{REFERENCES}

(1) Ito, A.; Penner, J. E. Historical emissions of carbonaceous aerosols from biomass and fossil fuel burning for the period 18702000. Global Biogeochem. Cycles 2005, 19, GB2028.

(2) Bond, T. C.; Streets, D. G.; Yarber, K. F.; Nelson, S. M.; Woo, J.H.; Klimont, Z. A technology-based global inventory of black and organic carbon emissions from combustion. J. Geophys. Res.: Atmos. 2004, 109, D14203.

(3) Hawthorne, S. B.; Krieger, M. S.; Miller, D. J.; Mathiason, M. B. Collection and quantitation of methoxylated phenol tracers for atmospheric pollution from residential wood stoves. Environ. Sci. Technol. 1989, 23, 470-475.

(4) Hawthorne, S. B.; Miller, D. J.; Langenfeld, J. J.; Krieger, M. S. PM-10 high-volume collection and quantitation of semi- and nonvolatile phenols, methoxylated phenols, alkanes, and polycyclic aromatic hydrocarbons from winter urban air and their relationship to wood smoke emissions. Environ. Sci. Technol. 1992, 26, 2251-2262.

(5) Myers-Pigg, A. N.; Griffin, R. J.; Louchouarn, P.; Norwood, M. J.; Sterne, A.; Cevik, B. K. Signatures of biomass burning aerosols in the plume of a saltmarsh wildfire in South Texas. Environ. Sci. Technol. 2016, 50, 9308-9314.

(6) Schauer, J. J.; Kleeman, M. J.; Cass, G. R.; Simoneit, B. R. T. Measurement of emissions from air pollution sources. 3. $\mathrm{C}_{1}-\mathrm{C}_{29}$ organic compounds from fireplace combustion of wood. Environ. Sci. Technol. 2001, 35, 1716-1728.

(7) Bruns, E. A.; El Haddad, I.; Slowik, J. G.; Kilic, D.; Klein, F.; Baltensperger, U.; Prévôt, A. S. H. Identification of significant precursor gases of secondary organic aerosols from residential wood combustion. Sci. Rep. 2016, 6, 27881.

(8) Lauraguais, A.; Coeur-Tourneur, C.; Cassez, A.; Deboudt, K.; Fourmentin, M.; Choël, M. Atmospheric reactivity of hydroxyl radicals with guaiacol (2-methoxyphenol), a biomass burning emitted compound: Secondary organic aerosol formation and gas-phase oxidation products. Atmos. Environ. 2014, 86, 155-163.

(9) Sagebiel, J. C.; Seiber, J. N. Studies on the occurrence and distribution of wood smoke marker compounds in foggy atmospheres. Environ. Toxicol. Chem. 1993, 12, 813-822.

(10) Yu, L.; Smith, J.; Laskin, A.; Anastasio, C.; Laskin, J.; Zhang, Q. Chemical characterization of SOA formed from aqueous-phase reactions of phenols with the triplet excited state of carbonyl and hydroxyl radical. Atmos. Chem. Phys. 2014, 14, 13801-13816.

(11) Feng, Y.; Ramanathan, V.; Kotamarthi, V. R. Brown carbon: a significant atmospheric absorber of solar radiation? Atmos. Chem. Phys. 2013, 13, 8607-8621.

(12) Laskin, A.; Laskin, J.; Nizkorodov, S. A. Chemistry of atmospheric brown carbon. Chem. Rev. 2015, 115, 4335-4382.

(13) Eugene, A. J.; Xia, S.-S.; Guzman, M. I. Aqueous photochemistry of glyoxylic acid. J. Phys. Chem. A 2016, 120, 3817-3826.

(14) Guzmán, M. I.; Colussi, A. J.; Hoffmann, M. R. Photoinduced oligomerization of aqueous pyruvic acid. J. Phys. Chem. A 2006, 110, 3619-3626.

(15) Xia, S.-S.; Eugene, A. J.; Guzman, M. I. Cross photoreaction of glyoxylic and pyruvic acids in model aqueous aerosol. J. Phys. Chem. A 2018, 122, 6457-6466.

(16) Hallquist, M.; Wenger, J. C.; Baltensperger, U.; Rudich, Y.; Simpson, D.; Claeys, M.; Dommen, J.; Donahue, N. M.; George, C.; Goldstein, A. H.; et al. The formation, properties and impact of secondary organic aerosol: current and emerging issues. Atmos. Chem. Phys. 2009, 9, 5155-5236.

(17) Shrivastava, M.; Cappa, C. D.; Fan, J.; Goldstein, A. H.; Guenther, A. B.; Jimenez, J. L.; Kuang, C.; Laskin, A.; Martin, S. T.; $\mathrm{Ng}$, N. L.; et al. Recent advances in understanding secondary organic aerosol: Implications for global climate forcing. Rev. Geophys. 2017, $55,509-559$.

(18) IPCC, Climate change 2013: The physical science basis. Contribution of working group I to the fifth assessment report of the intergovernmental panel on climate change; Cambridge University Press: Cambridge, United Kingdom and New York, NY, USA, 2013; p 1535.

(19) von Schneidemesser, E.; Monks, P. S.; Allan, J. D.; Bruhwiler, L.; Forster, P.; Fowler, D.; Lauer, A.; Morgan, W. T.; Paasonen, P.; Righi, M.; et al. Chemistry and the linkages between air quality and climate change. Chem. Rev. 2015, 115, 3856-3897.

(20) Pillar, E. A.; Camm, R. C.; Guzman, M. I. Catechol oxidation by ozone and hydroxyl radicals at the air-water interface. Environ. Sci. Technol. 2014, 48, 14352-14360.

(21) Pillar, E. A.; Guzman, M. I. Oxidation of substituted catechols at the air-water interface: Production of carboxylic acids, quinones, and polyphenols. Environ. Sci. Technol. 2017, 51, 4951-4959. 


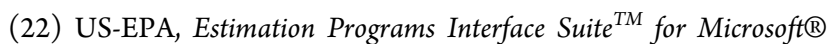
Windows, $v$ 4.11; United States Environmental Protection Agency: Washington, DC, USA, 2012.

(23) Huang, D. D.; Zhang, Q.; Cheung, H. H. Y.; Yu, L.; Zhou, S.; Anastasio, C.; Smith, J. D.; Chan, C. K. Formation and evolution of aqSOA from aqueous-phase reactions of phenolic carbonyls: Comparison between ammonium sulfate and ammonium nitrate solutions. Environ. Sci. Technol. 2018, 52, 9215-9224.

(24) Pillar, E. A.; Guzman, M. I.; Rodriguez, J. M. Conversion of iodide to hypoiodous acid and iodine in aqueous microdroplets exposed to ozone. Environ. Sci. Technol. 2013, 47, 10971-10979.

(25) Pillar-Little, E.; Guzman, M. An overview of dynamic heterogeneous oxidations in the troposphere. Environments 2018, 5, 104.

(26) Andreae, M. O.; Talbot, R. W.; Andreae, T. W.; Harriss, R. C. Formic and acetic acid over the central Amazon region, Brazil: 1. Dry season. J. Geophys. Res.: Atmos. 1988, 93, 1616-1624.

(27) Hu, Q.; Xie, Z.; Wang, X.; Kang, H.; Zhang, Y.; Ding, X.; Zhang, P. Monocarboxylic and dicarboxylic acids over oceans from the East China Sea to the Arctic Ocean: Roles of ocean emissions, continental input and secondary formation. Sci. Total Environ. 2018, 640-641, 284-292.

(28) Kawamura, K.; Tachibana, E.; Okuzawa, K.; Aggarwal, S. G.; Kanaya, Y.; Wang, Z. F. High abundances of water-soluble dicarboxylic acids, ketocarboxylic acids and $\alpha$-dicarbonyls in the mountaintop aerosols over the North China Plain during wheat burning season. Atmos. Chem. Phys. 2013, 13, 8285-8302.

(29) Smith, J. D.; Kinney, H.; Anastasio, C. Phenolic carbonyls undergo rapid aqueous photodegradation to form low-volatility, lightabsorbing products. Atmos. Environ. 2016, 126, 36-44.

(30) Vione, D.; Albinet, A.; Barsotti, F.; Mekic, M.; Jiang, B.; Minero, C.; Brigante, M.; Gligorovski, S. Formation of substances with humic-like fluorescence properties, upon photoinduced oligomerization of typical phenolic compounds emitted by biomass burning. Atmos. Environ. 2019, 206, 197-207.

(31) Andreae, M. O.; Merlet, P. Emission of trace gases and aerosols from biomass burning. Global Biogeochem. Cycles 2001, 15, 955-966.

(32) Alves, C. A.; Gonçalves, C.; Pio, C. A.; Mirante, F.; Caseiro, A.; Tarelho, L.; Freitas, M. C.; Viegas, D. X. Smoke emissions from biomass burning in a Mediterranean shrubland. Atmos. Environ. 2010, 44, 3024-3033.

(33) Keene, W. C.; Sander, R.; Pszenny, A. A. P.; Vogt, R.; Crutzen, P. J.; Galloway, J. N. Aerosol pH in the marine boundary layer. J. Aerosol Sci. 1998, 29, 339-356.

(34) Veres, P.; Roberts, J. M.; Burling, I. R.; Warneke, C.; de Gouw, J.; Yokelson, R. J. Measurements of gas-phase inorganic and organic acids from biomass fires by negative-ion proton-transfer chemicalionization mass spectrometry. J. Geophys. Res. 2010, 115, D23302.

(35) Stockwell, C. E.; Veres, P. R.; Williams, J.; Yokelson, R. J. Characterization of biomass burning emissions from cooking fires, peat, crop residue, and other fuels with high-resolution protontransfer-reaction time-of-flight mass spectrometry. Atmos. Chem. Phys. 2015, 15, 845-865.

(36) Gilman, J. B.; Lerner, B. M.; Kuster, W. C.; Goldan, P. D.; Warneke, C.; Veres, P. R.; Roberts, J. M.; de Gouw, J. A.; Burling, I. R.; Yokelson, R. J. Biomass burning emissions and potential air quality impacts of volatile organic compounds and other trace gases from fuels common in the US. Atmos. Chem. Phys. 2015, 15, 13915-13938. (37) Lefohn, A. S.; Shadwick, D.; Oltmans, S. J. Characterizing changes in surface ozone levels in metropolitan and rural areas in the United States for 1980-2008 and 1994-2008. Atmos. Environ. 2010, 44, 5199-5210.

(38) Parrish, D. D.; Law, K. S.; Staehelin, J.; Derwent, R.; Cooper, O. R.; Tanimoto, H.; Volz-Thomas, A.; Gilge, S.; Scheel, H.-E.; Steinbacher, M.; et al. Long-term changes in lower tropospheric baseline ozone concentrations at northern mid-latitudes. Atmos. Chem. Phys. 2012, 12, 11485-11504.
(39) Cooper, O. R.; Gao, R.-S.; Tarasick, D.; Leblanc, T.; Sweeney, C. Long-term ozone trends at rural ozone monitoring sites across the United States, 1990-2010. J. Geophys. Res. 2012, 117, D22307.

(40) Oltmans, S. J.; Lefohn, A. S.; Shadwick, D.; Harris, J. M.; Scheel, H. E.; Galbally, I.; Tarasick, D. W.; Johnson, B. J.; Brunke, E.G.; Claude, H.; et al. Recent tropospheric ozone changes - A pattern dominated by slow or no growth. Atmos. Environ. 2013, 67, 331-351.

(41) Eugene, A. J.; Pillar, E. A.; Colussi, A. J.; Guzman, M. I. Enhanced acidity of acetic and pyruvic acids on the surface of water. Langmuir 2018, 34, 9307-9313.

(42) Guzman, M. I.; Athalye, R. R.; Rodriguez, J. M. Concentration effects and ion properties controlling the fractionation of halides during aerosol formation. J. Phys. Chem. A 2012, 116, 5428-5435.

(43) Pillar, E. A.; Zhou, R.; Guzman, M. I. Heterogeneous oxidation of catechol. J. Phys. Chem. A 2015, 119, 10349-10359.

(44) Serjeant, E. P.; Dempsey, B. Ionisation Constants of Organic Ccids in Aqueous Solution; Pergamon Press, 1979; p 988.

(45) Net, S.; Alvarez, E. G.; Gligorovski, S.; Wortham, H. Heterogeneous reactions of ozone with methoxyphenols, in presence and absence of light. Atmos. Environ. 2011, 45, 3007-3014.

(46) Robinson, R. A.; Kiang, A. K. The ionization constants of vanillin and two of its isomers. Trans. Faraday Soc. 1955, 51, 13981402.

(47) Ragnar, M.; Lindgren, C. T.; Nilvebrant, N.-O. $\mathrm{pK}_{\mathrm{a}}$-values of guaiacyl and syringyl phenols related to lignin. J. Wood Chem. Technol. 2000, 20, 277-305.

(48) Steenken, S.; O'Neill, P. Oxidative demethoxylation of methoxylated phenols and hydroxybenzoic acids by the hydroxyl radical. An in situ electron spin resonance, conductometric pulse radiolysis and product analysis study. J. Phys. Chem. 1977, 81, 505508.

(49) Smith, J. Organic Chemistry; McGraw-Hill Education: New York, 2010

(50) Aracri, E.; Tzanov, T.; Vidal, T. Use of cyclic voltammetry as an effective tool for selecting efficient enhancers for oxidative bioprocesses: Importance of $\mathrm{pH}$. Ind. Eng. Chem. Res. 2013, 52, 1455-1463.

(51) Pye, H. O. T.; Nenes, A.; Alexander, B.; Ault, A. P.; Barth, M. C.; Clegg, S. L.; Collett, J. L., Jr.; Fahey, K. M.; Hennigan, C. J.; Herrmann, H.; et al. The acidity of atmospheric particles and clouds. Atmos. Chem. Phys. 2020, 20, 4809-4888.

(52) Parmar, R. S.; Satsangi, G. S.; Kumari, M.; Lakhani, A.; Srivastava, S. S.; Prakash, S. Study of size distribution of atmospheric aerosol at Agra. Atmos. Environ. 2001, 35, 693-702.

(53) Paulot, F.; Jacob, D. J. Hidden cost of U.S. agricultural exports: Particulate matter from ammonia emissions. Environ. Sci. Technol. 2014, 48, 903-908.

(54) Alves, C. A.; Gonçalves, C.; Pio, C. A.; Mirante, F.; Caseiro, A.; Tarelho, L.; Freitas, M. C.; Viegas, D. X. Smoke emissions from biomass burning in a Mediterranean shrubland. Atmos. Environ. 2010, 44, 3024-3033.

(55) Lin, P.-C.; Wu, Z.-H.; Chen, M.-S.; Li, Y.-L.; Chen, W.-R.; Huang, T.-P.; Lee, Y.-Y.; Wang, C. C. Interfacial solvation and surface $\mathrm{pH}$ of phenol and dihydroxybenzene aqueous nanoaerosols unveiled by Aerosol VUV Photoelectron Spectroscopy. J. Phys. Chem. B 2017, 121, 1054-1067.

(56) Rao, Y.; Subir, M.; McArthur, E. A.; Turro, N. J.; Eisenthal, K. B. Organic ions at the air/water interface. Chem. Phys. Lett. 2009, 477, 241-244.

(57) Ragnar, M.; Eriksson, T.; Reitberger, T. Radical Formation in Ozone Reactions with Lignin and Carbohydrate Model Compounds. Holzforschung 1999, 53, 292.

(58) Zhou, W.; Mekic, M.; Liu, J.; Loisel, G.; Jin, B.; Vione, D.; Gligorovski, S. Ionic strength effects on the photochemical degradation of acetosyringone in atmospheric deliquescent aerosol particles. Atmos. Environ. 2019, 198, 83-88.

(59) Lauraguais, A.; Bejan, I.; Barnes, I.; Wiesen, P.; Coeur, C. Rate coefficients for the gas-phase reactions of hydroxyl radicals with a 
series of methoxylated aromatic compounds. J. Phys. Chem. A 2015, 119, 6179-6187.

(60) Sandhiya, L.; Kolandaivel, P.; Senthilkumar, K. Mechanism and kinetics of the atmospheric oxidative degradation of dimethylphenol isomers initiated by OH radical. J. Phys. Chem. A 2013, 117, 46114626.

(61) von Gunten, U. Ozonation of drinking water: Part I. Oxidation kinetics and product formation. Water Res. 2003, 37, 1443-1467.

(62) Flyunt, R.; Leitzke, A.; Mark, G.; Mvula, E.; Reisz, E.; Schick, R.; von Sonntag, C. Determination of ${ }^{\bullet} \mathrm{OH}, \mathrm{O}_{2}{ }^{\bullet-}$, and hydroperoxide yields in ozone reactions in aqueous solution. J. Phys. Chem. B 2003, 107, 7242-7253.

(63) Mvula, E.; von Sonntag, C. Ozonolysis of phenols in aqueous solution. Org. Biomol. Chem. 2003, 1, 1749-1756.

(64) Bard, A. J.; Faulkner, L. R. Electrochemical Methods: Fundamentals and Applications, 2nd ed.; John Wiley \& Sons, Inc.: Phoenix, 2001.

(65) Koppenol, W. H. The reduction potential of the couple $\mathrm{O}_{3} /$ $\mathrm{O}_{3}^{\circ}$. FEBS Lett. 1982, 140, 169-172.

(66) Elliot, A. J.; McCracken, D. R. Effect of temperature on Oreactions and equilibria: A pulse radiolysis study. Int. J. Radiat. Appl. Instrum., Part C 1989, 33, 69-74.

(67) Anglada, J. M.; Martins-Costa, M.; Francisco, J. S.; Ruiz-López, $\mathrm{M}$. F. Interconnection of reactive oxygen species chemistry across the interfaces of atmospheric, environmental, and biological processes. Acc. Chem. Res. 2015, 48, 575-583.

(68) Mvula, E.; Naumov, S.; von Sonntag, C. Ozonolysis of lignin models in aqueous solution: Anisole, 1,2-dimethoxybenzene, 1,4dimethoxybenzene, and 1,3,5-trimethoxybenzene. Environ. Sci. Technol. 2009, 43, 6275-6282.

(69) Net, S.; Nieto-Gligorovski, L.; Gligorovski, S.; Temime-Rousell, B.; Barbati, S.; Lazarou, Y. G.; Wortham, H. Heterogeneous lightinduced ozone processing on the organic coatings in the atmosphere. Atmos. Environ. 2009, 43, 1683-1692.

(70) Criegee, R. Mechanism of ozonolysis. Angew. Chem., Int. Ed. $1975,14,745-752$.

(71) Herrmann, H.; Schaefer, T.; Tilgner, A.; Styler, S. A.; Weller, C.; Teich, M.; Otto, T. Tropospheric aqueous-phase chemistry: Kinetics, mechanisms, and its coupling to a changing gas phase. Chem. Rev. 2015, 115, 4259-4334.

(72) Chen, X.; Sun, Y.; Qi, Y.; Liu, L.; Xu, F.; Zhao, Y. Mechanistic and kinetic investigations on the ozonolysis of biomass burning products: Guaiacol, syringol and creosol. Int. J. Mol. Sci. 2019, 20, 4492.

(73) Ten Brink, G.-J.; Arends, I. W. C. E.; Sheldon, R. A. The Baeyer- Villiger reaction: New developments toward greener procedures. Chem. Rev. 2004, 104, 4105-4124.

(74) O’Neill, E. M.; Kawam, A. Z.; Van Ry, D. A.; Hinrichs, R. Z. Ozonolysis of surface-adsorbed methoxyphenols: kinetics of aromatic ring cleavage vs. alkene side-chain oxidation. Atmos. Chem. Phys. 2014, $14,47-60$.

(75) Mahal, H. S.; Badheka, L. P.; Mukherjee, T. Radical scavenging properties of a flavouring agent-Vanillin. Res. Chem. Intermed. 2001, 27, 595-604.

(76) Arakaki, T.; Anastasio, C.; Kuroki, Y.; Nakajima, H.; Okada, K.; Kotani, Y.; Handa, D.; Azechi, S.; Kimura, T.; Tsuhako, A.; et al. A general scavenging rate constant for reaction of hydroxyl radical with organic carbon in atmospheric waters. Environ. Sci. Technol. 2013, 47, 8196-8203.

(77) Seinfeld, J. H.; Pandis, S. N. Atmospheric Chemistry and Physics: From Air Pollution to Climate Change, 2nd ed.; Wiley, 2006; p 1232.

(78) Tomaz, S.; Cui, T.; Chen, Y.; Sexton, K. G.; Roberts, J. M.; Warneke, C.; Yokelson, R. J.; Surratt, J. D.; Turpin, B. J. Photochemical cloud processing of primary wildfire emissions as a potential source of secondary organic aerosol. Environ. Sci. Technol. 2018, 52, 11027.

(79) Ehn, M.; Thornton, J. A.; Kleist, E.; Sipilä, M.; Junninen, H.; Pullinen, I.; Springer, M.; Rubach, F.; Tillmann, R.; Lee, B.; et al. A large source of low-volatility secondary organic aerosol. Nature 2014, 506, 476. 